\title{
Alternative splicing of the pituitary adenylate cyclase-activating polypeptide receptor PAC1: mechanisms of fine tuning of brain activity
}

\author{
Janna Blechman and Gil Levkowitz * \\ Department of Molecular Cell Biology, Weizmann Institute of Science, Rehovot, Israel
}

\section{Edited by:}

Hubert Vaudry, University of Rouen,

France

\section{Reviewed by:}

Hubert Vaudry, University of Rouen, France

Atsuro Miyata, Kagoshima University, Japan

*Correspondence:

Gil Levkowitz, Department of

Molecular Cell Biology, Weizmann

Institute of Science, P. O. Box 26,

Rehovot 76100, Israel.

e-mail: gil.levkowitz@weizmann.ac.il
Alternative splicing of the precursor mRNA encoding for the neuropeptide receptor PAC1/ADCYAP1R1 generates multiple protein products that exhibit pleiotropic activities. Recent studies in mammals and zebrafish have implicated some of these splice isoforms in control of both cellular and body homeostasis. Here, we review the regulation of PAC1 splice variants and their underlying signal transduction and physiological processes in the nervous system.

Keywords: ADCYAP1R1, activity-dependent gene regulation, zebrafish model system, PACAP receptor, stress disorders, post-traumatic, hypothalamic hormones, homeostasis

\section{INTRODUCTION}

G-protein-coupled receptors (GPCRs) represent the largest family of membrane-associated proteins mediating physiological responses in vertebrates by means of controlling metabolic, neural, and developmental functions (Lefkowitz, 2007; Frooninckx et al., 2012; Zhang and Eggert, 2013). These proteins are expressed in almost all types of tissues and are represented by over 1,000 membrane receptors for extracellular (EC) ligands including hormones, neurotransmitters, pheromones, lipids, and other proteins (Xue et al., 2008; Markovic and Grammatopoulos, 2009; Nordstrom et al., 2009; Hoyer and Bartfai, 2012; Jafurulla and Chattopadhyay, 2013). The basic structure of GPCR proteins consists of a seven-transmembrane (TM) domain with a complex EC structure composed of an N-terminal region and three EC loops involved in the diverse ligand recognition process. Three intracellular (IC) loops and a C-terminal domain transduce a signal into the cell's cytoplasm and nucleus. Typically, ligand binding to the EC loops induces conformational changes in the TM and IC domains of the receptor resulting in specific coupling to a set of cytoplasmic molecules, termed G-proteins, each composed of different isoforms of alpha, beta, and gamma subunits. G-proteins in turn regulate the activity of IC effector molecules, including adenylate cyclase (AC), phospholipase $\mathrm{C} \beta$ (PLC), and RhoGEF causing the activation of secondary messengers such as cyclic AMP (cAMP), inositol-1,4,5triphosphate (InP3), and diacylglycerol leading to the initiation of distinct IC signaling pathways (Simon et al., 1991; Sah et al., 2000; Pierce et al., 2002; Oldham and Hamm, 2008; Mizuno and Itoh, 2009; Mahata et al., 2011; Maurice et al., 2011).

The diversity of the GPCR-initiated signal transduction pathways is determined by the multiplicity of cognate ligands with different receptor binding properties and by the receptors' membrane-interacting partners that form homo- and hetero-dimerized GPCR complexes. These receptor dimers have unique binding properties to both EC ligands and a set of IC G-proteins (Milligan and Kostenis, 2006; Harikumar et al., 2008; Furness et al., 2012). Thus, ligand binding, along with receptor heterodimerization, can generate diversity in G-proteins coupling that can generate varied IC signaling functions.

Beyond the complexity of the aforementioned EC and IC GPCRs interacting effectors, the genetic diversity of the GPCR family can be generated by means of alternative precursor mRNAs (pre-mRNA) splicing of exons encoding specific protein moieties and causing considerable functional differences of the resulting splicing products (Black, 2003; Jaillon et al., 2008; Furness et al., 2012). Alternative splicing mechanisms allow the generation of multiple mRNA transcript variants from a single gene by utilizing different combinations of exons by means of skipping or insertion of alternatively spliced exons. In particular, neuronal cells are known to exhibit high levels of alternative splicing, generating the basis for molecular and cellular diversity important for the patterning and maintenance of the central and peripheral nervous systems (Yeo et al., 2007; Betke et al., 2012; Norris and Calarco, 2012; Sun et al., 2012). In the case of GPCRs, this combinatorial exon assembly can lead to changes in the protein domains responsible for ligand binding, IC effector coupling, as well as receptor stability, and endocytosis.

In this review we focus on one GPCR, the pituitary ACactivating polypeptide (PACAP) receptor (ADCAYP1R1), also known as PAC1. This receptor represents a fascinating example of how alternative splicing of a single GPCR gene leads to different physiological outcomes. We will describe the current knowledge regarding the role and mechanism of action of PAC1 splice variants in development, physiology, and diseases focusing on PACl's role in the nervous system. 


\section{THE PAC1 RECEPTOR}

PAC1 belongs to the glucagon/secretin receptor family of GPCRs that consists of hormone and neuropeptide receptors. These receptors signal through coupling to the G-protein alpha subunits $\mathrm{Gs}$ and $\mathrm{Gq}$ that typically activate $\mathrm{AC}$ and phospholipase $\mathrm{C} \beta$ enzymes, respectively (McCulloch et al., 2002; Ahren, 2008; Dickson and Finlayson, 2009; Vallejo, 2009; Vaudry et al., 2009). Coupling of PAC1 to Gs may also lead to cAMPdependent accumulation of IC calcium (Braas and May, 1996; Mustafa et al., 2010). The PAC1 gene contains multiple exons that undergo extensive alternative splicing. The peptide PACAP is the high-affinity ligand for PACl. Post-translational proteolytic processing of the PACAP precursor protein generates several polypeptides with varying sizes, including PACAP38 and PACAP27 (Miyata et al., 1989; Vaudry et al., 2009; Harmar et al., 2012; Watkins et al., 2012). PAC1 was found to play a pivotal role in the spatio-temporal regulation of proliferation, differentiation, or cell survival during development as well as in the regulation of synthesis and release of neuroendocrine hormones.

Phylogenetic analysis of the vertebrate PAC1 receptor family indicates their origin from a common ancestral gene and demonstrates a tree topology with species-specific paralogs belonging to different separated sub-groups (Figure 1). Bony fishes (teleosts) genomes typically contain more than one gene due to teleostspecific gene duplication event of both ligand and receptor molecules during the evolution of these species (Wei et al., 1998; Fradinger et al., 2005; Bjarnadottir et al., 2006; Cardoso et al., 2007; Machluf et al., 2011).

\section{ALTERNATIVELY SPLICED PAC1 GENE PRODUCTS}

The alternative splicing of PAC1 has been extensively studied. In this review we use the exon numbers designation of the human $P A C 1$ and otherwise indicate cases where the exons numbers do not match. The human gene was shown to contain 18 exons with the open reading frame encoded by exons 2-18 (Chatterjee et al., 1997; Lutz et al., 2006). Ten of these exons are constitutively expressed (exons 2, 3, 7-13, 18), whereas the rest (exons $4-6,14,15$, and possibly 16,17 ) are regulated by the alternative splicing (Figure 2). The N-terminal part of PAC1's EC domain is encoded by six exons. Exons 7-17 encode the seven-TM domains including EC and IC loops and exon 18 encodes the C-terminal cytoplasmic tail including the $3^{\prime}$-untranslated region (Figures 2 and 3). PAC1 splicing variants were identified in other vertebrate species including rat, mouse, frog, and fish. In Table 1 we assembled all known PAC1 splice isoforms from different vertebrate species. The functional outcome of these splicing events will be discussed later. By and large, PAC1 alternative splicing can be divided into four types of splicing events that impact receptor functions (Figure 3; Table 1): (1) Variations in the EC $\mathrm{N}$-terminal domain altering the ligand-binding specificity and affinity. (2) Variations in exons encoding to part of the third IC loop (IC3) thereby affecting G-protein coupling and/or interaction with other IC signaling proteins. (3) Variations in the TM domains TM2 and TM4 contributing to the receptors heteromerization and IC transport. (4) Variations in the 5' UTR that may affect mRNA expression dynamics. Notably, splicing products

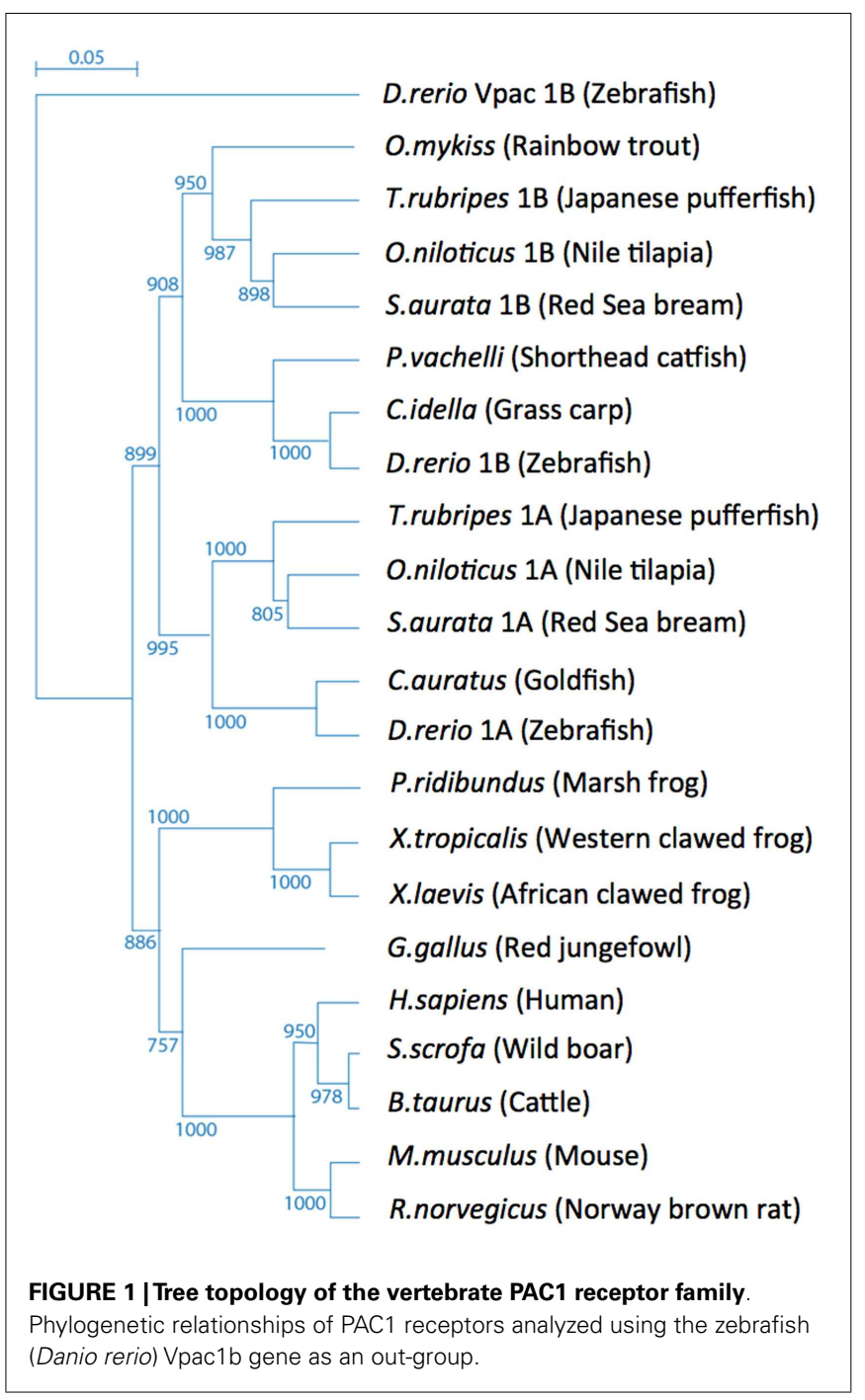

containing different combinations of $\mathrm{N}$-terminal and IC3 splice variants were identified in mammalian species.

The terminology used in independent studies can be somewhat perplexing as different names were designated to PAC1 isoforms corresponding to the same splicing events identified in various species. In the following section we describe the various splice variants and indicate when a different (i.e., specie-specific) name was designated to the same isoform. A splice isoform that includes all $\mathrm{N}$-terminal encoding exons but does not contain IC (IC3) insertion(s) is referred to as "PAC1-null" (Table 1). The ligand binding and signaling properties of PAC1-null are often used as a reference when assessing the activities of other splice variants.

\section{N-TERMINAL VARIATIONS}

The N-terminal variants were identified in rodents and humans but not in fishes to date. They are generated by alternative splicing of exon 5 (PAC1- $\delta 5)$, exons 5-6 (PAC1-short or PAC1- 55,6$)$, or exons 4-6 (PAC1-very short or PAC1- $\delta 4,5,6)$ leading to deletions of 7, 21, or 57 amino acids, respectively (Journot et al., 1994; 


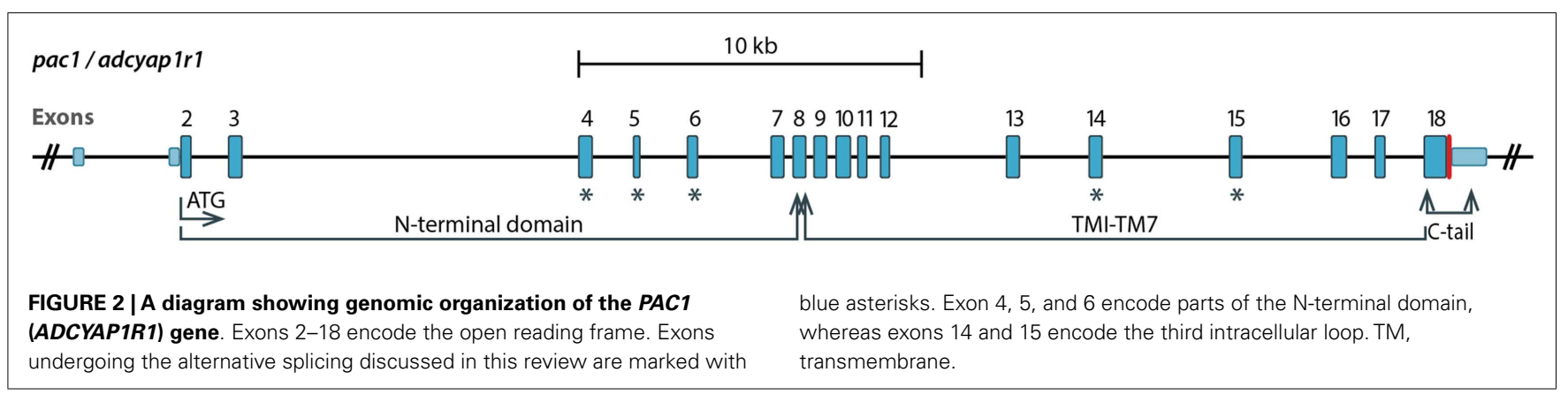

Pantaloni et al., 1996; Chatterjee et al., 1997; Dautzenberg et al., 1999; Lutz et al., 2006; Ushiyama et al., 2007, 2010). In the rat, an insertion of 24 amino acids is caused by splicing of a novel exon 3a located between exons 3 and 4 (PAC1-3a) (Figure 3) (Daniel et al., 2001; Ajpru et al., 2002; Pilzer and Gozes, 2006a). N-terminal splicing isoforms of PAC1 display alterations both in ligand-binding selectivity and coupling to second messengers compared to PAC1-null.

\section{INTRACELLULAR LOOP VARIATIONS}

PAC1 splice variants in the third IC loop (IC3) have been identified in human, amphibian, fishes, and rodents. These splice isoforms are characterized by the presence of one or two cassettes of 84 nucleotides (hip or hop1 variants) or 81 nucleotides (hop2 variant), or a combination of alternative spliced "cassettes" (hip-hop1 or hip-hop2) (Spengler et al., 1993; Journot et al., 1995; Grimaldi and Cavallaro, 1999; McCulloch et al., 2001; Ronaldson et al., 2002; Fradinger et al., 2005; Ushiyama et al., 2007; May et al., 2010; Holighaus et al., 2011). In human, hip and hop variants are also referred to as SV1 and SV2 or SV3 for hip-hop1 (Pisegna and Wank, 1996; Pisegna et al., 1996). In addition, a splice variant formed by a C-terminal deletion of 193 nucleotides (denoted "hop1 novel") including two amino acids that are essential for G-protein recognition was identified in rat cochlea samples (Abu-Hamdan et al., 2006). Similar alternative splicing variants of PAC1 are also found in non-mammalian vertebrates such as the frog and bony fishes. Three alternative splice variants were identified in the frog IC3 loop (Alexandre et al., 2002). PAC1-R25, with an insertion of 25 amino acids, corresponds to the mammalian hop cassette. PAC1-R41 contains a cassette with no homology to any other variant. PAC1-RMc with a unique cytoplasmic insertion of 13 amino acid into the TM7 domain is missing a canonical Gs recognition motif. PAC1 genes were also identified in zebrafish, goldfish, stickleback, fugu, sea bream, and several others bony fish species. Three zebrafish PAC1 alternative splice variants with insertions in the IC3 loop were identified. Two of them were found to be homologous to the hop1 (84 nucleotides) and hop2 (81 nucleotides) mammalian isoforms (Fradinger et al., 2005). A unique 107 nucleotides inclusion with a premature stop codon (PAC1-skip) resulting in a truncated PAC1 protein did not correspond to any previously detected PAC1 isoform (Fradinger et al., 2005). This isoform resembles an alternative splicing event in a human gene encoding another secretin family receptor, VPAC1. Interestingly, the hip cassette variant was not identified in the mouse and zebrafish genomes. Moreover, teleosts genomes contain two (duplicated)
PAC1 paralogs, pacla and pac1b, however, only pacla encodes for the hop splicing cassette.

\section{TRANSMEMBRANAL DOMAIN VARIATIONS}

A PAC1 variant, cloned from the rat cerebellum, has amino acids deletion/substitution in the TM4 domain along with two amino acid substitutions in the N-terminal (D136N) and TM2 (N190D) domains (Chatterjee et al., 1996; Ajpru et al., 2002). The exact molecular mechanism underlying these variations remains unclear. Notably, the TM4 domain of the secretin family receptors are involved in homo- and hetero-oligomerization of these receptors, associations with receptor activity-modifying proteins (RAMPs), and with GPCR kinases (GRKs) thereby suggesting that splice alterations in the PAC1-TM4 domain may affect receptor function (Morfis et al., 2003; Ritter and Hall, 2009; Magalhaes et al., 2012).

\section{5' UTR VARIATIONS}

Alternative splicing events in exons located at the $5^{\prime}$ UTR were identified for rat PAC1 gene (Chatterjee et al., 1997). These include different alternative usage of exons located upstream to the ATG translation start codon. Such variations in the $5^{\prime}$ UTR organization and sequences may play a role in the regulation of mRNA expression.

\section{ALTERNATIVE PAC1 SPLICING ALTERS LIGAND-BINDING PROPERTIES}

$\mathrm{PACl}$ is considered as being the high-affinity receptor for PACAP, while it displays low binding affinity to the vasoactive intestinal polypeptide (VIP) (Apostolakis et al., 2005; Vaudry et al., 2009; Harmar et al., 2012). Alternative splicing of PAC1 results in different protein products displaying different ligand-binding properties that may result in changes in affinity and selectivity (Table 1). Most studies use the PAC1-null (McCulloch et al., 2001; Holighaus et al., 2011) isoform as a reference for PACAP and VIP binding properties.

Modeling of ligand-receptor binding proposes that the $\mathrm{C}$ terminal part of the ligand PACAP binds to the N-terminus of the PAC1 receptor and that the N-terminal part of PACAP binds to the receptor's EC loops and TM domains (Furness et al., 2012). Consequently, alterations in the $\mathrm{EC}$ domain of $\mathrm{PACl}$ are predicted to affect these ligand-receptor binding properties (Table 1). Thus, PAC1-very short (a.k.a. PAC1- $44,5,6$ ), which lacks 57 amino acids in the EC1 domain displays decreased affinity to PACAP27 and PACAP38 but its affinity toward VIP remains the same (Journot 


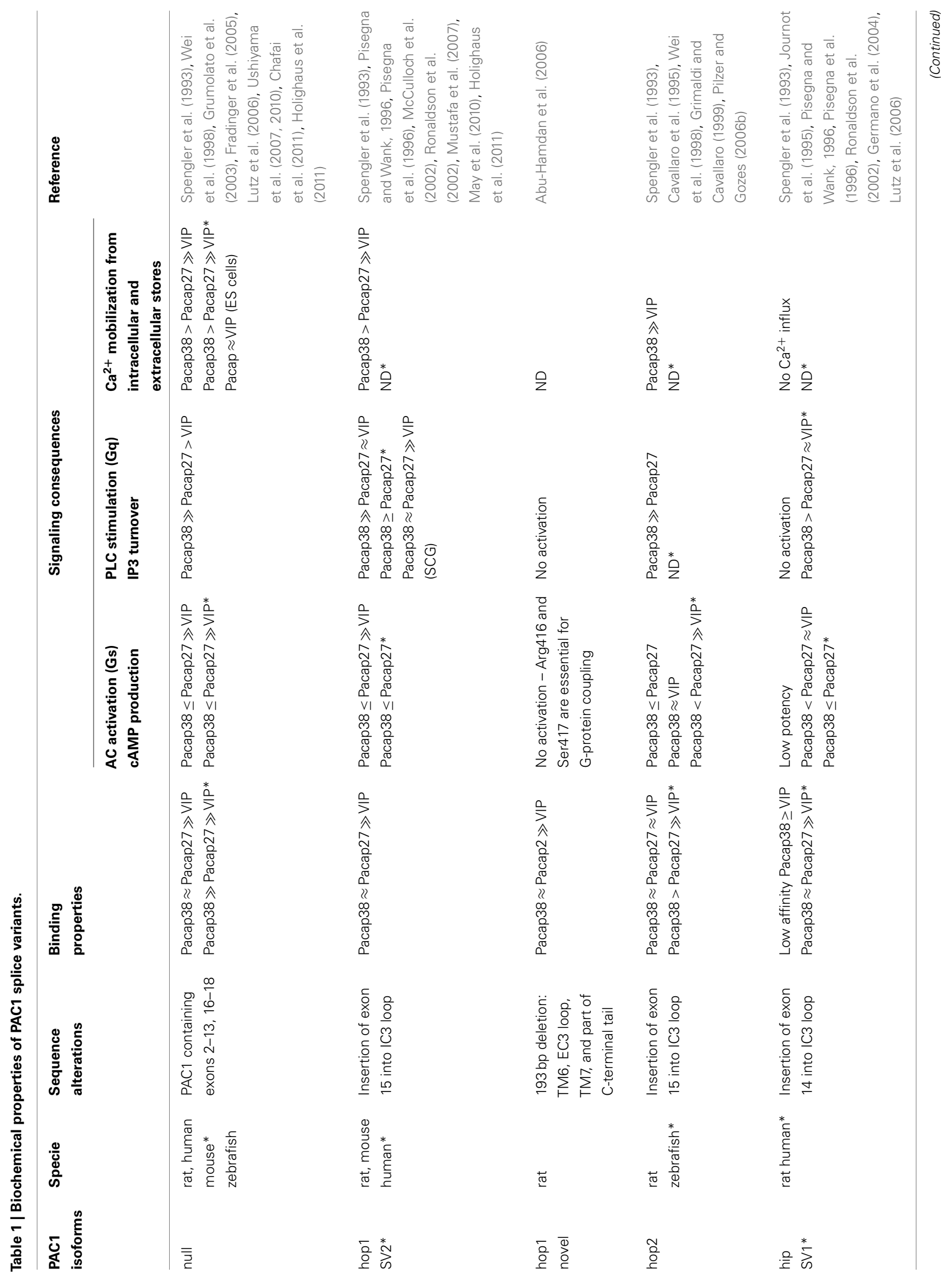




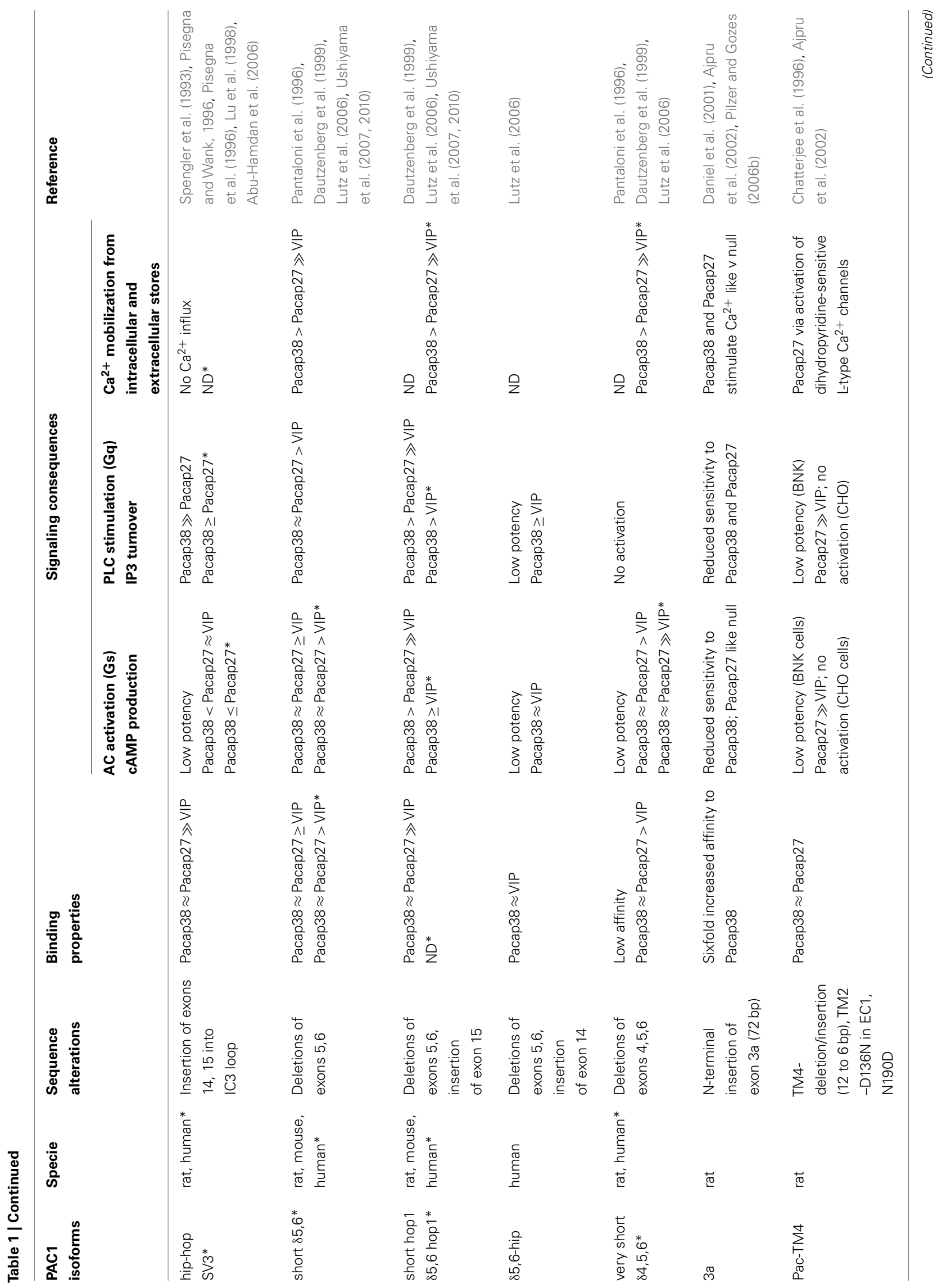




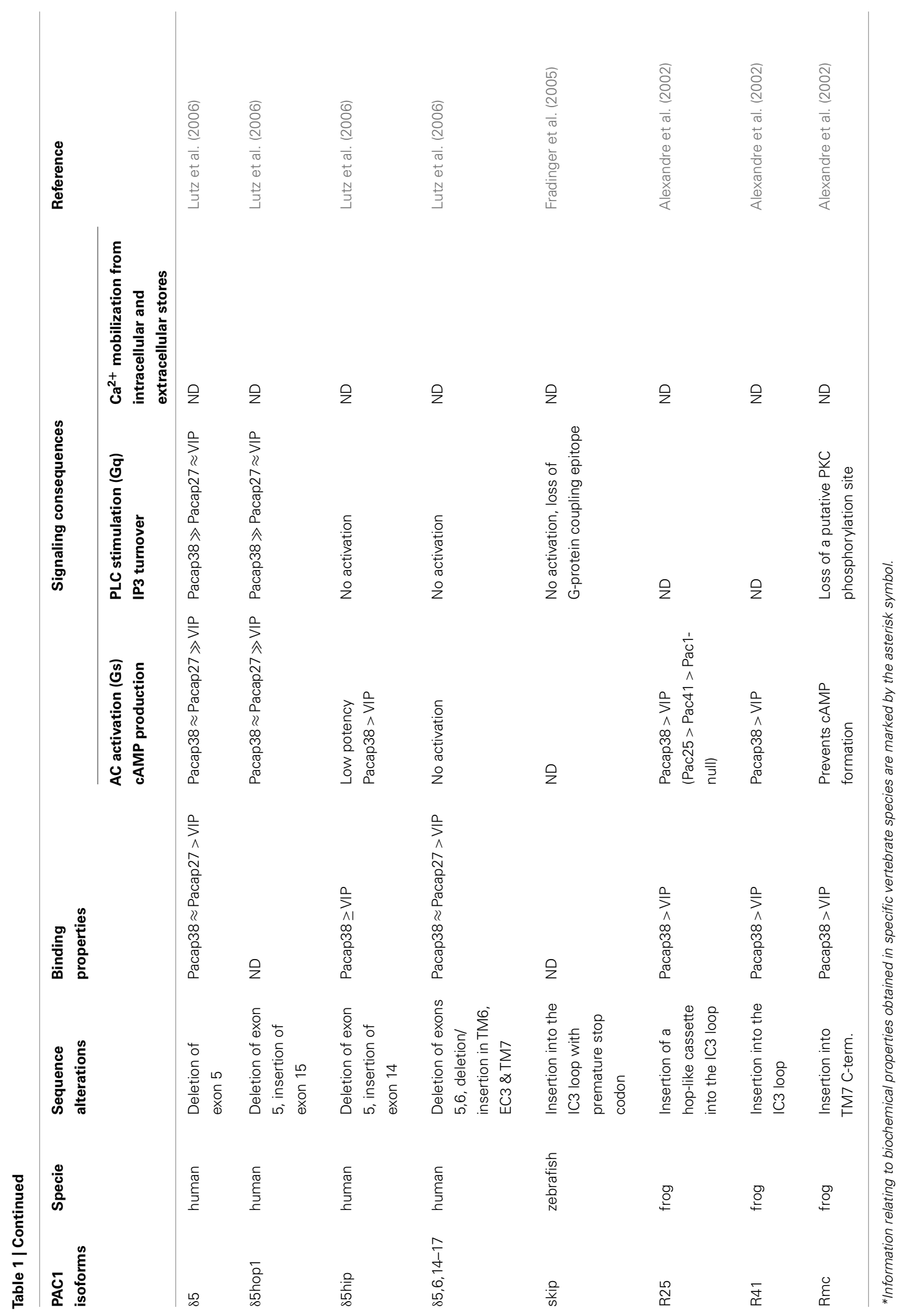




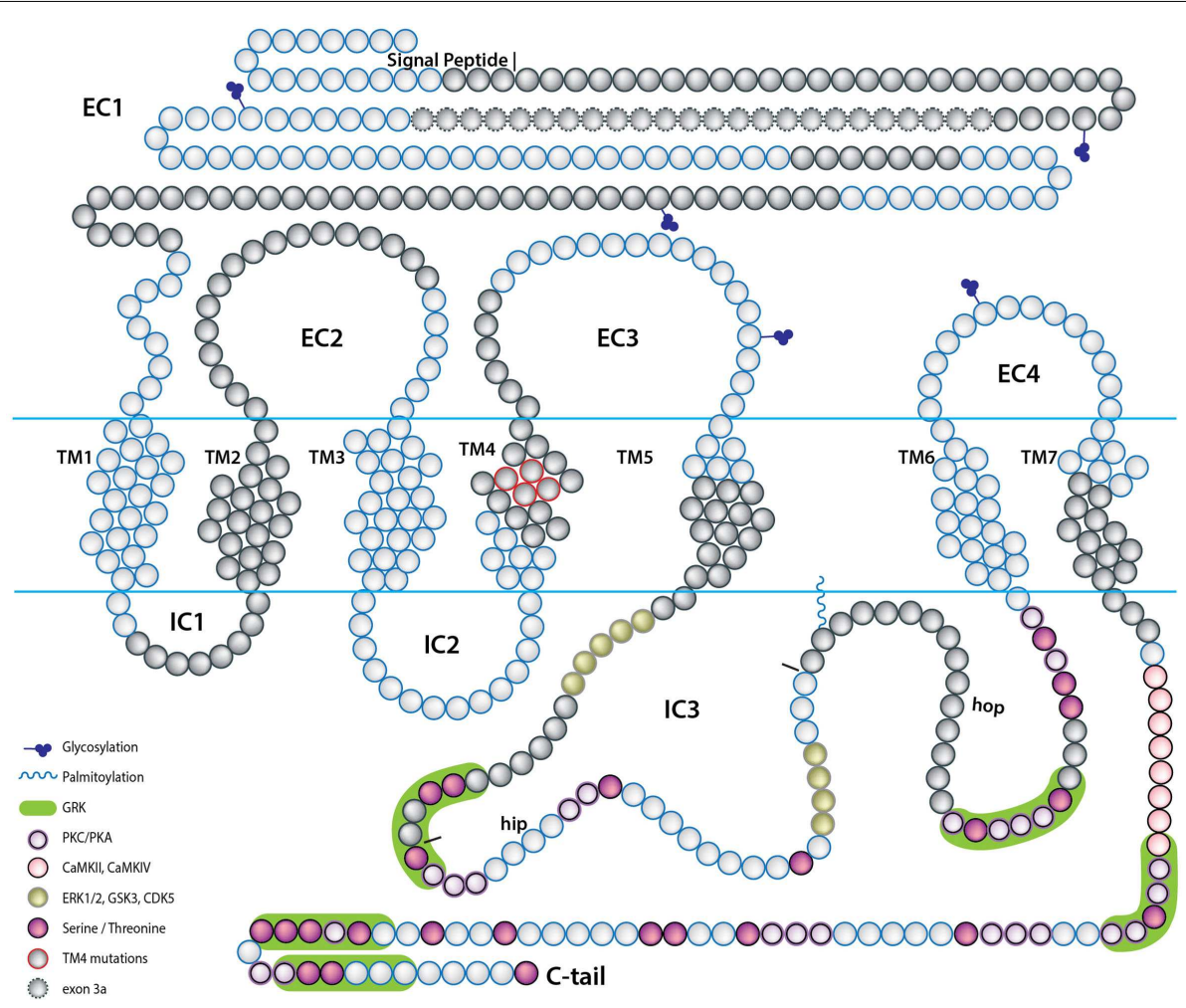

FIGURE 3 |A scheme depicting the topology of the PAC1 receptor. The relative location of amino acids encoded by PAC1 exons are depicted by the blue and gray beads. Predicted PAC1 structural motifs known to be involved in protein-protein interactions determining G-protein mediated
PAC1 signaling are marked on the protein diagram with regard to putative motifs formed due to insertions of hop and hip cassettes into the IC3 loop sequence. EC, extracellular loop; IC, intracellular loop; TM, transmembrane domain. et al., 1995; Pantaloni et al., 1996; Dautzenberg et al., 1999; Lutz et al., 2006). The binding affinities for PACAP38 of the $\delta 5, \delta 5,6$ (a.k.a. short) splice isoforms appeared to be very similar to that of PAC1-null, while $\delta 5,6$ isoform has increased affinity toward VIP. The rat-specific PAC1-3a isoform containing a 24 residue $\mathrm{N}$-terminal insertion displays increased affinity to PACAP38 but not to PACAP27 (Daniel et al., 2001; Pilzer and Gozes, 2006a). It should be noted that in all of these examples, PACAP is still the better ligand for PAC1 when compared with VIP (Table 1).

The hop1 and hip-hop1 splice isoforms retain similar binding properties to those of PAC1-null. In contrast, insertions into the IC3 loop, namely hip- and hop2-cassettes lead to the elevation of VIP (Spengler et al., 1993; Pisegna et al., 1996; Pilzer and Gozes, 2006b) and the diminution of PACAP binding affinities, thereby suggesting that the alteration in IC3 causes an inside-out conformational change.

Notably, binding analysis of alternative spliced isoforms, which result from combined changes in the EC and IC protein domains yields interesting results. Thus, a splice variant composed of PAC1short with the inclusion of hop1-cassette, displays similar PACAP and VIP binding properties to that of PAC1-null and different VIP binding properties than PAC1-short alone (Lutz et al., 2006; Ushiyama et al., 2007, 2010). Another combined splice variant composed of PAC1- $\delta 5$ or PAC1- $\delta 5,6$ together with the hip cassette had different ligand-binding properties to that of PAC1, PAC1- $\delta 5$, or PAC1-hip alone (Lutz et al., 2006) (Table 1). This imply that the IC3 domain contributes to the association of PAC1 with its cognate ligands.

These results may be explained by a model for agonist binding to the corticotropin-releasing hormone $(\mathrm{CRH})$ receptor, which belongs to the same GPCR sub-family of PAC1 (Dong et al., 2005). According to this model the TM6 protein domain plays a structural role in ligand binding. Thus, insertions into IC3 loop, which is located between TM5 and TM6 region may cause a conformational change in TM6 and possibility affect binding of PACAP and VIP to the EC part of the receptor. A proof for this model awaits a solved three-dimensional protein structural of the different PAC1 isoforms.

\section{ALTERNATIVE PAC1 SPLICING ALTERS INTRACELLULAR SIGNAL TRANSDUCTION}

Ligand binding to PAC1 results in allosteric changes in the IC docking sites for effector coupling. A variety of IC signal transduction cascades can be differentially transduced by multiple PAC1 splice variants with altered EC or IC protein domains (Figure 4) (Arimura, 1998; Dickson and Finlayson, 2009; Vaudry et al., 2009; Furness et al., 2012). The most studied pathways include coupling of PAC1 to Gs and Gq proteins and activation of AC and phospholipase C $\beta$ PLC $\beta$ ) which result in the respective stimulation of production of cAMP and/or IP3 (Milligan and Kostenis, 2006; 


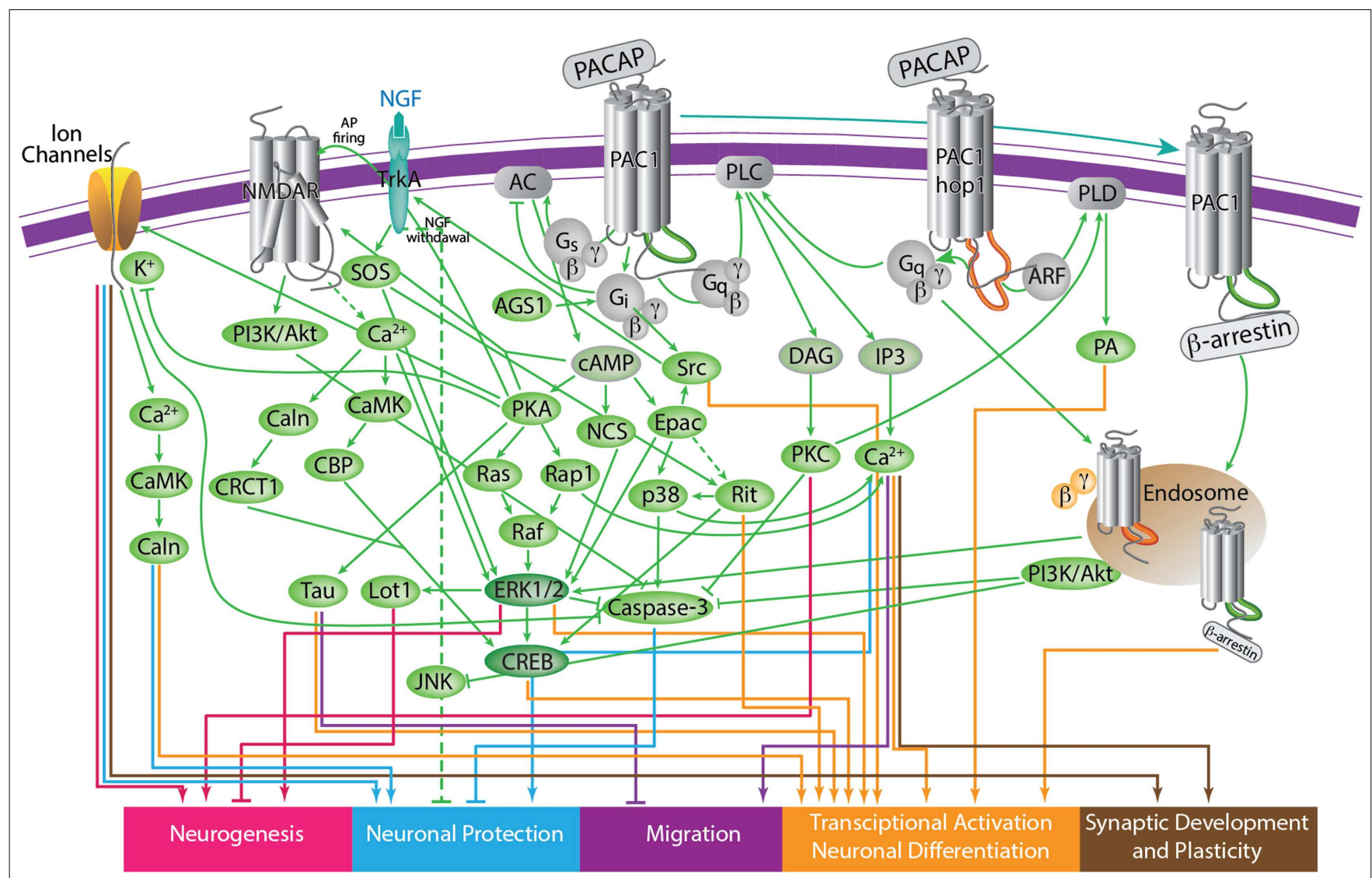

FIGURE 4 | A scheme depicting the current knowledge on PAC1-mediated signaling cascades resulting in a variety of neuronal outcomes. PKA was shown to induce ERK1/2 thereby contributing to PACAP neuroprotective Nillalba et al., 1997; Vaudry et al., 2003; Falluel-Morel et al., 2006; Stumm et al., 2007) and neurotrophic (Ravni et al., 2006; Botia et al., 2007; Monaghan et al., 2008) functions. Action potential (AP) firing induces a CRCT1/CREB mediated neuroprotective effect, presumably through NMDA receptor activation and was shown to be initiated by PKA activation (Baxter et al., 2011). NMDA receptor was also shown to be indirectly activated by PACAP (Llansola et al., 2004) or CAMP/PKA signaling (Costa et al., 2009). PAC1/PKA signaling controls cellular apoptosis through inhibition of potassium channels (Mei et al., 2004; Castel et al., 2006; Pugh and Margiotta, 2006) or induction of calcium channels (Pugh and Margiotta, 2006). PAC1/PKA-mediated activation of ion channels leads to activity-dependent neuronal differentiation and synaptic plasticity (Lee et al., 1999; Maturana et al., 2002; Grumolato et al., 2003; Nishimoto et al., 2007). The tumor suppressor gene Lot1 known as a negative regulator of neuronal precursor proliferation was shown to be controlled by PAC1/cAMP/ERK signaling pathway (Fila et al., 2009). PAC1/PKA-dependent phosphorylation of Tau is involved in the control of granule cell migration during cerebellar development (Falluel-Morel et al. 2006). PAC1-mediated CAMP/ERK-dependent neurite outgrowth was shown to be regulated via a novel neuritogenic factor NCS (Emery and Eiden, 2012) or Epac/ERK (Gerdin and Eiden, 2007) pathways. PAC1/Epac was shown to regulate neuronal differentiation via activation of p38 kinase along with mobilization of $\mathrm{Ca}^{2+}$ from intracellular stores (Ster et al., 2007) as well as Epac/Rit-dependent pathway involving CREB signaling (Shi et al., 2006). PAC1 was demonstrated to induce Rit through TrkA/Shc/SOS signaling initiated by
Src activation via dual Gs/Epac and Gi stimulation (Shi et al., 2010). PACAP also signals through Gq-linked PLC $>$ IP3 $>\mathrm{Ca}^{2+} / \mathrm{DAG}>\mathrm{PKC}$, and PLD > phosphatidic acid (PA) pathways (Journot et al., 1994; Makhlouf and Murthy, 1997; Dejda et al., 2006). PAC1 is a mediator of gene transcription, neuronal differentiation, and synaptic development (Masmoudi-Kouki et al., 2006; Vaudry et al., 2007; Andero and Ressler, 2012). As an example of functional diversity caused by PAC1 alternative splicing two additional PAC1-hop1 signaling pathways are presented on the scheme. They depict PAC1-hop1/ARF dependent PLD activation (McCulloch et al., 2001) and internalization-dependent engagement of PI3K $\gamma /$ Akt activation (May et al., 2010). AC, adenylate cyclase; AGS, activator of G protein signaling; Akt, serine-threonine protein kinase PKB; CAMP, cyclic adenosine monophosphate; ARF, ADP(adenosine diphosphate) ribosylation factor; Caln, calcineurin; CaMK, calcium calmodulin kinase; CBP, creb binding protein; CRCT1, cysteine-rich C-terminal 1; CREB, CAMP responsive element-binding protein; DAG, diacyl glycerol; Epac, exchange factor directly activated by CAMP; ERK, extracellular signal-regulate kinase; G, guanine nucleotide-binding regulatory protein; IP3, inositol-1,4,5-triphosphate; JNK, c-Jun oncogene N-terminal kinase 1; Lot1, lost on transformation 1; NCS, neuritogenic cAMP sensor; NGF, nerve growth factor; NMDAR, $N$-methyl-d-aspartate receptor; p38, p38 mitogen-activated protein kinase; $\mathrm{PA}$, phosphatidic acid; $\mathrm{PI} 3 \mathrm{~K}$, phosphatidylinositol 3' OH kinase; PKA, protein kinase A; PKC, protein kinase C;PLC, phospholipase; Raf, B-Raf proto-oncogene serine/threonine kinase; Ras, retrovirus-associated DNA sequences; Rap1, Rit, small GTPases of the RAS oncogene family; Sos, son of sevenless homolog 1; Src, sarcoma viral oncogen homolog; Tau, neuron-specific microtubule-associated protein; TrkA, tropomyosin-related kinase.
Couvineau and Laburthe, 2012) (Figures 3 and 4). In addition, PAC1 was shown to regulate the level of IC $\mathrm{Ca}^{2+}$ in either $\mathrm{G}$ protein dependent or independent manners. The following section reviews the role of PAC1 splice variants in the activation of the above pathways as well as other non-canonical signaling cascades (see also Table 1). 


\section{AC AND PLC $\beta$}

When compared to the PAC1-null isoform, some alternative spliced variants display altered mode of signaling. For example, PAC1 isoform 3a, $\delta 4,5,6$ (a.k.a. very short), hip, hip-hop, $\delta 5$-hip, and 85,6 -hip show reduction in the potency of agonists-mediated cAMP and IP3 production (Spengler et al., 1993; Dautzenberg et al., 1999; Parsons et al., 2000; Daniel et al., 2001; Germano et al., 2004; Lutz et al., 2006; Pilzer and Gozes, 2006a; Holighaus et al., 2011). Similarly, PAC-TM4, hop1 novel, $85,6,14-17$, skip, and Rmc have lost their ability to stimulate cAMP and IP3 production (Chatterjee et al., 1996; Daniel et al., 2001; Ajpru et al., 2002; Alexandre et al., 2002; Fradinger et al., 2005; Abu-Hamdan et al., 2006; Pilzer and Gozes, 2006a). Notably, all of the above splice variants have modified or deleted IC3, TM, and C-terminal protein domains that are known to be important for G-protein binding (Chatterjee et al., 1996).

In some studies, PAC1-null displays very low or no activation of PLC $\beta$ while PAC1-hop1 switches its mode of signaling from AC to PLC $\beta$ (Spengler et al., 1993; DiCicco-Bloom et al., 2000; Nicot and DiCicco-Bloom, 2001; Ronaldson et al., 2002; May et al., 2010). For example, PAC1-hop1 was reported to mediate the activation of both $\mathrm{AC}$ and phospholipase $\mathrm{C}$ signaling in cortical sympathetic neuroblasts, while PAC1-null merely signals via AC stimulated pathway (Braas and May, 1996; DiCicco-Bloom et al., 2000). Other studies report that both isoforms display dual activation of $\mathrm{AC}$ and PLC $\beta$ pathways, however the hop1 isoform has higher activation of these pathways. Thus, analyses of SV1/hip and SV2/hop1 show that these isoforms display increased coupling to cAMP and PLC $\beta$, respectively (Spengler et al., 1993; Pisegna and Wank, 1996; Lu et al., 1998; Braas and May, 1999; Parsons et al., 2000; Nicot and DiCicco-Bloom, 2001; Germano et al., 2004; Lutz et al., 2006; May et al., 2010; Holighaus et al., 2011). The frog R25 and R41 isoforms containing amino acid insertions into IC3 have higher activation of cAMP compared to PAC1-null (Alexandre et al., 2002).

Consistent with the effect of IC3 loop insertions on ligandbinding properties, hip- and hop2-cassettes conferred comparable potency to induction of cAMP and IP3 accumulation by PACAP and VIP but at the same time characterized by much lower efficacy of this response (Spengler et al., 1993; Pisegna and Wank, 1996; Pisegna et al., 1996; Ronaldson et al., 2002; Lutz et al., 2006). On the other hand, PAC1-hip variant was shown to retain AC mediated signaling but demonstrated impaired coupling to the PLC $\beta$ pathway (May et al., 2010).

\section{CA $^{2+}$ SIGNALING}

The concentration of calcium ions $\left(\mathrm{Ca}^{2+}\right)$ in the cytoplasm is controlled by its uptake and release by specific transporter proteins residing in the plasma membrane, the inner mitochondria membrane, and the endoplasmic reticulum (ER) (Clapham, 2007). PAC1-mediated $\mathrm{Ca}^{2+}$ signaling was shown to play important roles in regulating neurotransmitter release, and neurotransmitter receptors (Shioda et al., 1997; Taupenot et al., 1999; Germano et al., 2009; Mustafa et al., 2010; Pugh et al., 2010; Amir-Zilberstein et al., 2012; Smith and Eiden, 2012). The effects of PAC1 splice isoforms on the levels of cytoplasmic $\mathrm{Ca}^{2+}$ were reported in the cases of PAC1-null hop1/2, 85,6/short, 3a, and PAC1-TM4 (Table 1) (Dautzenberg et al., 1999; Lutz et al., 2006; Mustafa et al., 2007,
2010; Nishimoto et al., 2007; Germano et al., 2009; Hansson et al., 2009; Vallejo, 2009; Ushiyama et al., 2010; Holighaus et al., 2011). PACAP is known to modulate both $\mathrm{EC} \mathrm{Ca}^{2+}$ influx via voltagegated calcium channels (VGCC) and $\mathrm{Ca}^{2+}$ release from IC ER stores through both IP3/PLC $\beta$ and AC pathways but also through other signaling cascades (Tanaka et al., 1997; Shioda et al., 1998; Grimaldi and Cavallaro, 1999).

PAC1-null was reported to modulate cytosolic $\mathrm{Ca}^{2+}$ mobilization from both EC and IC stores (Shioda et al., 1997; Masmoudi et al., 2003; Payet et al., 2003; Nishimoto et al., 2007). In acutely dissociated rat melanotrophs, the increase of cytosolic $\mathrm{Ca}^{2+}$ was dependent on the activation of non-selective cation channels and the facilitation of voltage-dependent $\mathrm{Ca}^{2+}$ channels by PKCand PKA-dependent phosphorylation, respectively (Tanaka et al., 1997). cAMP-dependent entry of EC calcium was also reported in astrocyte cells (Vallejo, 2009). It was also suggested that PAC1null-mediated elevation of cytoplasmic $\mathrm{Ca}^{2+}$ levels in NG108-15 cells is due to $\mathrm{IP}_{3}$ receptor-mediated $\mathrm{Ca}^{2+}$ release from IC stores (Holighaus et al., 2011).

The PAC1-hop1 variant is responsible for both $\mathrm{Ca}^{2+}$ mobilization from IC stores and influx through voltage-gated $\mathrm{Ca}^{2+}$ channels in bovine chromaffin cells (Mustafa et al., 2007). Transfection of PAC1-hop to the adrenomedullary pheochromocytoma (PC12) cell line showed sustained $\mathrm{IP}_{3}$-mediated $\mathrm{Ca}^{2+}$ release from IC stores and from store-operated $\mathrm{Ca}^{2+}$ entry (SOCE) (Taupenot et al., 1999; Mustafa et al., 2007, 2010). In bovine adrenal chromaffin cells, PAC1-hop was shown to mediate cytosolic $\mathrm{Ca}^{2+}$ release from ryanodine/caffeine-sensitive $\mathrm{Ca}^{2+}$ stores that was not dependent on either cAMP or IP3 generation (Tanaka et al., 1998; Payet et al., 2003). Heterologous expression of the rat PAC1-hop1 but not PAC1-hip variant in NG108-15 and PC12 cells leads to an increase in IC $\mathrm{Ca}^{2+}$ concentration (Mustafa et al., 2007; Holighaus et al., 2011). In both cell lines the response consisted of a rapid and transient rise of $\mathrm{Ca}^{2+}$ reminiscent of $\mathrm{IP}_{3}$ receptor-mediated $\mathrm{Ca}^{2+}$ release from IC stores followed by a prolonged $\mathrm{Ca}^{2+}$ accumulated from EC source.

When compared with PAC1-null, PAC1-hop1 was more potent in $\mathrm{Ca}^{2+}$ elevation (Holighaus et al., 2011). However, following overexpression in Chinese Hamster Ovarian cells, activation of PAC1-null induced higher $\mathrm{Ca}^{2+}$ levels when compared with activation of PAC1-hop1 (Ushiyama et al., 2010). PAC1-hop1 also mediated PACAP-induced $\mathrm{Ca}^{2+}$ release from ER and PKC $\gamma$ translocation to the nucleus and plasma membrane resulting in the astrocytic differentiation (Nicot and DiCicco-Bloom, 2001). Finally, stimulation of voltage-gated L-type or non L-type $\mathrm{Ca}^{2+}$ channels following initiation of PAC1-hop1 signaling was also reported (Mustafa et al., 2010).

Somewhat limited data was reported with regards to $\mathrm{Ca}^{2+}$ signaling via other PAC1 splice variants. Thus, $\delta 5,6 /$ short as well as the PAC1 isoform containing combined "short" deletion in the $\mathrm{N}$-terminal EC1 domain along with hop1-cassette in the IC3 loop exhibit PACAP-induced cytoplasmic calcium elevation (Ushiyama et al., 2010). PAC1-3a was shown to induce $\mathrm{Ca}^{2+}$ accumulation through coupling to Gs/cAMP rather than Gq/PLC $\beta$ pathway (Pilzer and Gozes, 2006a). PAC1-TM4 that was found to be inactive when assayed for both cAMP and PLC $\beta$ activation but it displayed elevation of $\mathrm{Ca}^{2+}$ in response to PACAP27. It was demonstrated 
that this effect involved the modulation of voltage-gated L-type $\mathrm{Ca}^{2+}$ channels (Chatterjee et al., 1996).

Taken together, the apparent inconsistent results concerning the mechanisms underlying the aforementioned $\mathrm{Ca}^{2+}$ signaling events are most likely due to the different cellular systems (e.g., cell types) employed by the above studies to analyze PAC1-mediated IC $\mathrm{Ca}^{2+}$ changes.

\section{OTHER TRANSDUCTION PATHWAYS}

Signaling of PAC1 through interaction with cytoplasmic protein partners, other than the canonical Gs and Gq, was reported mainly in the case of the PAC1-hop1 isoform (McCulloch et al., 2001; Ronaldson et al., 2002). Both PAC1-null and -hop1 proteins were reported to activate phospholipase D (PLD). Although PAC1-nullmediated PLD stimulation involved Gq/11 > PLC > PLD pathway, PAC1-hop1 was capable of activating PLD through direct binding to ADP-ribosylation factor (ARF) (McCulloch et al., 2002; Dejda et al., 2006).

\section{EXPRESSION OF PAC1 SPLICE ISOFORMS IN THE NERVOUS SYSTEM}

Information on time- and region-specific distribution of PAC1 splice isoforms may shed light on how PAC1 gene products regulate a plethora of biological functions in developmental and physiological processes (D'Agata et al., 1996; Waschek et al., 2000; Waschek, 2003; Vaudry et al., 2009). The distribution of PAC1 has been examined in many species using different techniques that revealed widespread expression in different tissues, including the nervous, cardiovascular, endocrine, immune, and respiratory systems (Aino et al., 1995; Abu-Hamdan et al., 2006; Gomariz et al., 2006; Molnar et al., 2008; Jolivel et al., 2009; Shneider et al., 2010; Lugo et al., 2011; Buljan et al., 2012). However, knowledge concerning the expression of PAC1 splice variants is somewhat limited at it is mainly based on analyses of isolated brain areas and/or primary cell cultures. The reported changes in PAC1 receptor variant expression appear to be most evident during development. We have summarized the existing data concerning the expression of these variants by focusing on expression in the nervous system of different mammalian species.

The major mRNA isoform of PAC1 in the brain is PAC1-null, which contains no splice deletions or insertions. PAC1-null is predominantly expressed in neurons residing in different brain areas although it is also detected in glial cells of the cerebella cortex and in activated astrocytes (Pilzer and Gozes, 2006b; Dickson and Finlayson, 2009; Vaudry et al., 2009).

$\mathrm{PAC1}$ variants with $\mathrm{N}$-terminal deletions are well represented in human fetal brain tissues and in five human neuroblastoma lines (Lutz et al., 2006; Falktoft et al., 2009), thereby suggesting their role in immature nervous tissue. $\mathrm{N}$-terminal splice variants were detected in different brain areas. The PAC1-short variant with 21 amino acids N-terminal deletion was predominantly found in the thalamus, hypothalamus, and the hypophysis, and more moderately in the amygdala and retina (Dautzenberg et al., 1999; Grimaldi and Cavallaro, 1999; Jamen et al., 2002; Girard et al., 2004; Lutz et al., 2006; Ushiyama et al., 2007, 2010; Hammack et al., 2010a). It was shown to be expressed in cochlea subfractions along with the PAC1- $\delta 5$ isoform with a seven amino acid deletion (Abu-Hamdan et al., 2006). The PAC1-very short variant (57 amino acid deletion) was also detected at low levels in the mouse amygdala and cortex though not in the retina. All three $\mathrm{N}$-terminal variants (null, short, and very short) were abundantly expressed in neuronal tissues (Dickson and Finlayson, 2009; Vaudry et al., 2009). The PAC1-3a variant containing $\mathrm{N}$-terminal insertion of 24 amino acids was detected in rat cerebral cortex. This splice isoform is also highly expressed in distinct cell populations of the testis, including Sertoli cells, pachytene spermatocytes, and round spermatids (Daniel et al., 2001; Ajpru et al., 2002; Pilzer and Gozes, 2006a).

Contrary to the aforementioned $\mathrm{N}$-terminal splice variants that were only reported in mammals, IC loops (i.e., IC3) splice products are found in all studied vertebrate species. In the postnatal cerebral cortex of rats, the expression of PAC1-null, hop1, hip, and hip-hop1 dramatically decreases during the first neonatal month suggesting a major role for these isoforms in embryonic development (Shneider et al., 2010). Interestingly, the expression of these isoforms was shown to be gender dependent displaying higher levels in female postnatal brain at least during the first 3 months of development. In the developing retina, the proportion of IC3 $\mathrm{PAC} 1$ isoforms changes as development proceeds: PAC1-hip-hop1 transcript demonstrated transient elevation at day P10, while a decrease in PAC1-null and hip along with elevation of PAC1hop1 level was observed by P20 (Lakk et al., 2012). PAC1-hop1 expression was found in the olfactory bulb, hippocampus, cerebral cortex, cerebellum, and striatum of newborn rats. PAC1-hop2 was present in rat cerebral astrocytes from newborn brains, in neuronal enriched cultures, and in PC12 cells that undergo neuronal differentiation following NGF treatment (Jamen et al., 2002; Onoue et al., 2002; Hashimoto et al., 2003; Ravni et al., 2006; Mustafa et al., 2010).

PAC1-hip was detected at much lower levels in adult tissues and it was therefore speculated to be important for the embryonic development (Shneider et al., 2010; Holighaus et al., 2011). The relative expression of human and rat PAC1 splice variants in the frontal cortex was reported to have the following expression level hierarchy: null $>$ SV1/hip $>$ SV2/hop $=$ SV3/hiphop (Pisegna and Wank, 1996; Pisegna et al., 1996; Germano et al., 2004; Lutz et al., 2006). PAC1-hop1 was found to be expressed in all neuroendocrine cells, suggesting a fine tuning of PAC1-mediated signaling in the neuroendocrine cells (Mustafa et al., 2010). PAC1hop1 splice isoform was the major form expressed in the superior cervical ganglia (SCG) sympathetic neurons, which also express PAC1-short (Braas and May, 1999). Zebrafish IC3 splice isoforms are widely expressed in the adult tissues with PAC1-hop1 detected in brain and testis, PAC1-hop2 in the ovary and PAC1-skip variant in the gills (Fradinger et al., 2005). Lastly, although PAC1-TM4 isoform is mainly found in pancreatic $\beta$-cells it is also expressed in the cerebral cortex, cerebellum, and brain stem (Chatterjee et al., 1996; Ajpru et al., 2002).

In summary, changes in $\mathrm{PAC1}$ receptor variant expression appear to be most evident during development. The fact that PAC1 splice variants display differential expression patterns in the nervous system suggests that alternative splicing of this gene product plays a role in fine tuning of PAC1 activity in these areas. 


\section{REGULATION OF PAC1 SPLICING BY NEURONAL-SPECIFIC RNA-BINDING PROTEINS}

The regulation of PAC1 splicing is not well understood. Alternative splicing of pre-mRNA is often regulated by conserved cis-regulatory RNA sequence elements that serve as recognition sites for different splicing factors. These RNA-binding splicing factors differ from the general spliceosome machinery proteins due to the formers' ability to either activate or repress the inclusion of alternatively spliced exons, depending on whether the factors' binding site is located upstream, downstream, or inside the exon. Neuronal-specific splicing factors include nova-1/2, Rbfox-1/2, and ELKV2 splicing factors, the neuronal-specific polypyrimidine tract-binding protein (nPTB) as well as a set of heterogeneous nuclear ribonucleoproteins (hnRNP A1,L,F.H1). As the consensus cis-acting binding sequences for the aforementioned splicing factors have been identified, their involvement in regulating the alternative splicing of a given gene by sequence analysis can be predicted. We analyzed the presence of known consensus binding sites for the following RNA-binding proteins: Rbfox-1/2, Nova- $1 / 2$ (single and repeatedly organized elements), SC-35, nPTB enhancers and silencers, and CaRRE for $\mathrm{Ca}^{2+} / \mathrm{CaM}$ kinase IV recognition sequences. Putative binding sites for neuronal-specific splicing factors in the respective PAC1 genes of human, mouse, and zebrafish are shown in Figure 5.

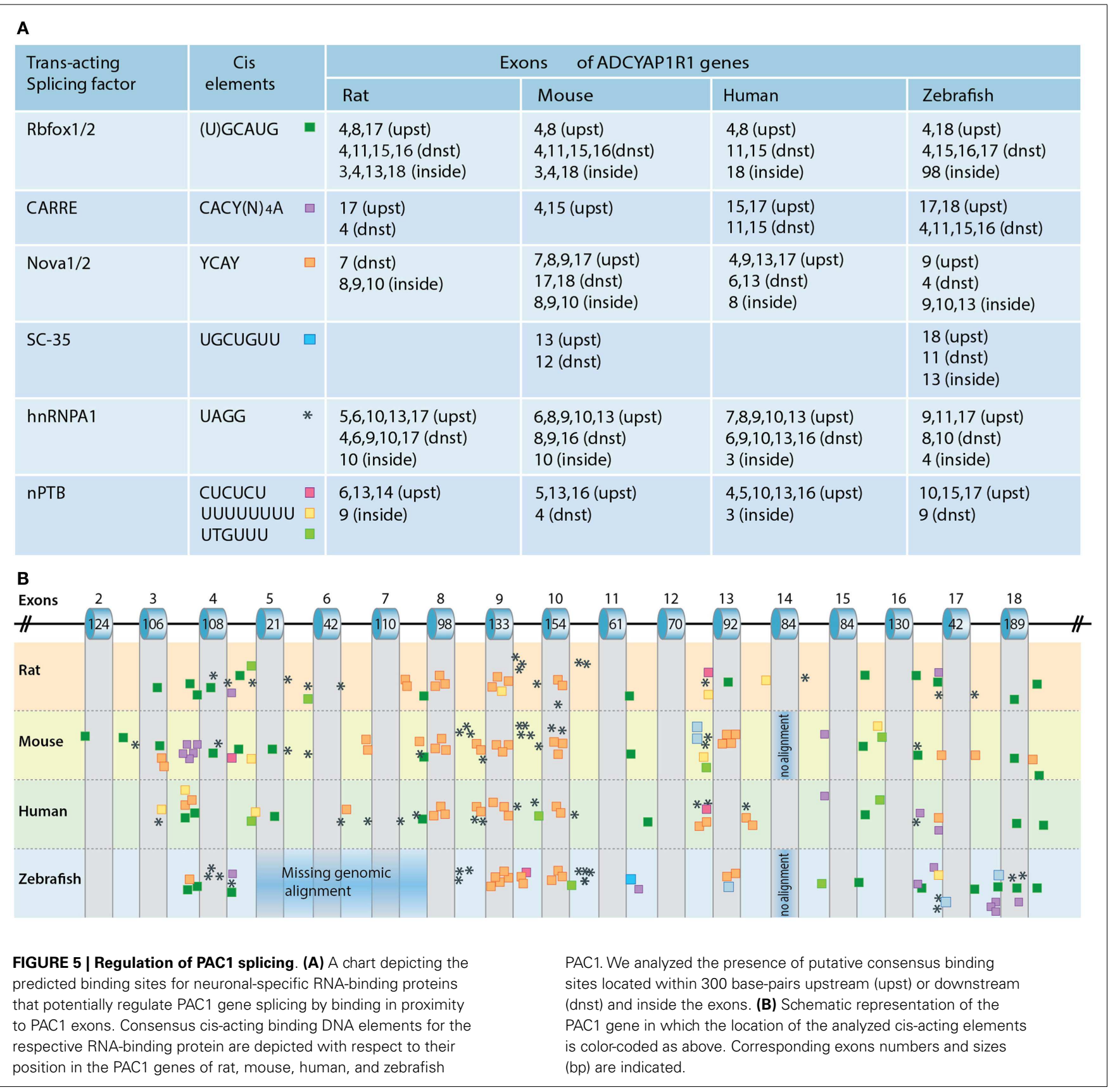


Rbfox-1/2 can act either as a splicing enhancer or as an inducer of exon skipping (Zhang et al., 2008). Putative Rbfox-1/2 binding sites located within a short distance downstream of target exons are predicted to induce exon inclusion whereas upstream binding sites are predicted to cause exon skipping. Such Rbfox-1/2 recognition element located within a short distance downstream of hop1 encoding exon has been experimentally validated as a genuine Rbfox-1 binding site (Lee et al., 2009). Our own PAC1 bioinformatic analysis identified a putative Rbfox-1/2 binding element within -30 nucleotides downstream from conserved exon spanning zebrafish TM7 suggesting that this domain might be regulated by alternative splicing (Figure 5). Rbfox-1/2 motifs are also present in the sequences of all examined species downstream of exon 16 encoding parts of the TM7 domain. Another recognition site is located upstream of exon 4 consistent with a deletion of the exon resulting in the generation of PAC1-very short splice variant (Figure 5). Rbfox-1/2 recognition motif predicts potential deletion of exon 8 that may result in a generation of a soluble PAC1 receptor as in the case of the CRH receptor ( $\mathrm{Zmi}$ jewski and Slominski, 2009, 2010). Rbfox-1/2 binding site is also detected downstream of exon 11, which is known to encode the most hypervariable amino acid sequence among Secretin family GPCRs, as well as part of TM4 domain which undergoes alternative splicing in PAC1-TM4 isoform (Markovic and Grammatopoulos, 2009).

Calcium signaling plays an important role in neuronal development and is involved in the regulation of immediate and long-term neuronal responses to various stimuli such as stressors and hormones (Ghosh et al., 1994; West et al., 2001). Depolarization is known to be critical for modulating the neuronal activity that induces $\mathrm{Ca}^{2+}$-dependent gene regulation, including alternative splicing. $\mathrm{Ca}^{2+}$-dependent splicing is mediated by L-type calcium channels and by $\mathrm{Ca}^{2+} /$ calmodulin-dependent protein kinases IV (CaMK IV) (Lee et al., 2007, 2009). The latter was shown to repress splicing of target genes containing specific recognition elements (CaRRE) located within the $3^{\prime}$ splice site or inside the exon. Our own analysis detected additional putative CaRREs that can be responsive to CaMK IV. We predicted single, multiple, and tandemly organized CaRRE repeats upstream of exon 15 and 17 of the zebrafish, human, and mouse PAC1 receptors, suggesting the involvement of CaMK IV in regulating the alternative splicing of these exons. Putative CaRREs are also present proximal to mouse, rat, and zebrafish exon 4 (Figure 5).

Exonic and intronic hnRNPA1 and nPTB cis-elements that are important for activity-dependent splicing in neuronal cells were shown to repress the inclusion of target exons (Allemand et al., 2005; An and Grabowski, 2007; Donev et al., 2007; Resnick et al., 2008; Zheng et al., 2012). Putative hnRNPA1 and nPTB recognition sites are located proximal to exons 4,5 , and 6 consistent with the known deletions of these exons that result in the generation of PAC1-short and very short splice variants. Putative hnRNPA1 recognition motifs are also found near exons 8-10 encoding to IC1, IC2, and EC2 domains (Figure 5).

Nova-1/2 regulates target exon inclusion or skipping with broad distribution of binding sites across the gene sequence (Ule et al., 2005; Yano et al., 2010; Norris and Calarco, 2012). Predicted
Nova-1/2 recognition elements are found in human and mouse PAC1 and in both paralogs of zebrafish PAC1 gene (1a and 1b). Interestingly, higher frequency of putative splicing-inducing AUrich and Nova-specific sequences are found in intronic regions upstream of alternative spliced exons characteristic of the Secretin family splicing patterns, e.g., around exon 4, 8, 9, 10 (Zmijewski and Slominski, 2009) as well as exon 17. Exons 4-6 encode sequences covering known N-terminal PAC1 deletion regions (deletions of 7, 21, and 57 amino acids). Exon 17 encodes the last amino acids of the seventh TM domain and the beginning of the IC tail shown to represent the highly conserved exon within the secretin family (Markovic and Grammatopoulos, 2009). Skipping of this exon was not detected in the PAC1 receptor gene, but it has been proposed that such exon skipping in the human CRF1 and PTH1 receptors results in a six TM receptor displaying impaired trafficking (Shyu et al., 1996; Grammatopoulos et al., 1999; Markovic et al., 2008). The rabbit calcitonin receptor is also formed as a result of the skipping of the TM7 domain and displays slightly diminished cAMP activation along with deficiency in IP3 induction (Shyu et al., 1996). Taken together the above analysis of potential cis-elements spanning TM7 exons predicts that a PAC1 splice variant containing TM7 skipping may exist in neuronal tissues.

An important question raised in this chapter is whether the aforementioned RNA-binding factors regulate PAC1 splicing in vivo. It has been demonstrated that alternative splicing of the PAC1 receptor is regulated by the Rbfox-1 splicing factor in depolarized neurons. In this case, neuronal depolarization induced CaM-kinase dependent self-splicing of Rbfox-1, leading to the translocation of Rbfox- $1 / 2$ from the cytoplasm to the nucleus where Rbfox- 1 could mediate the alternative splicing of neuronal-specific target genes, including PAC1. Interestingly, Rbfox-1 mRNA levels were shown to be regulated by the Orthopedia (Otp) homedomain-containing protein. The latter is a hypothalamic-specific transcriptional factor, which plays a role in hypothalamic neuronal-specification during development and in regulation of body homeostasis in the mature zebrafish brain (Acampora et al., 1999; Wang and Lufkin, 2000; Blechman et al., 2007; Ryu et al., 2007; Amir-Zilberstein et al., 2012; Fernandes et al., 2012). The involvement and regulation of other neuronal-specific RNA-binding factors in PAC1 splicing remains to be determined.

\section{PLEIOTROPIC ROLES OF PAC1 SPLICE ISOFORMS IN THE NERVOUS SYSTEM}

The distribution of PAC1 and its ligands PACAP and VIP in a variety of cell types is reminiscent of the pleiotropic functions of PAC1 in development and physiology. PACAP is described in the literature as a hormone, neuropeptide, endocrine peptide, neurotransmitter, and neurotrophic factor. It affects the central nervous system (CNS), cardiovascular system, pituitary, thyroid, and adrenal glands and provides functional activities in the gonads, gastrointestinal tract, and pancreas (Waschek et al., 2000; Dickson and Finlayson, 2009; Vaudry et al., 2009). In the nervous system, PAC1 was shown to affect a variety of hormones and neuropeptides, including stimulation of oxytocin (Jamen et al., 2003) and melatonin (Nakahara et al., 2002) release and de novo 
mRNA synthesis of CRH (Nakahara et al., 2002; Amir-Zilberstein et al., 2012), arginine-vasopressin (Murase et al., 1995; Gillard et al., 2006), GnRH (Kanasaki et al., 2009; Winters and Moore, 2011), somatostatin (Kageyama et al., 2007), and MSH (Mounien et al., 2006). This overabundance of PAC1-mediated physiological activities can be made possible through the signaling diversity of its alternatively spliced gene products. Moreover, different expression of PAC1 isoforms is common in neuronal ontogeny. Such differences in the expression of PAC1 splice variants might modulate final outputs of VIP and PACAP activities as neurotransmitters, neurotrophic, or differentiation factors. Examples for the involvement of PAC1 splice isoforms in mediating these activities are described below.

\section{NEUROGENESIS, NEUROPROTECTION, AND DIFFERENTIATION}

Neural progenitor cells (NPC) and astroglial cells express PAC1null and PAC1-hop1 variants that mediate both cAMP- and $\mathrm{Ca}^{2+}$ dependent signaling pathways and induce production of a subset of neurotrophic factors resulting in neuronal proliferation and/or differentiation. PAC1-hop2 variant, detected in astrogenic and neuronal populations, promote neuroprotective function induced by VIP. In another study, VIP was also demonstrated to induce PAC1-hop2-mediated astrocytes neuroprotection against oxidative stress. Astrocytic expression of PAC1-hop2 isoform may therefore play a critical role in the NPC shift toward neuronal or astrocytes differentiation (Ashur-Fabian et al., 1997; Pilzer and Gozes, 2006b).

Expression of PAC1-null and PAC1-hop1 define region-specific neurogenesis in the CNS and peripheral nervous systems (Lu et al., 1998). Both variants are differently expressed in proliferating sympathetic (PAC1-hop1) and cortical precursors (PAC1-null) revealing opposing PACAP-mediated mitogenic regulation - either by stimulating sympathetic neuroblast proliferation or by inhibiting cortical precursor mitosis. Ectopic expression of PAC1-hop1 in cortical neuroblasts may transform the anti-mitotic effect of PACAP into promitotic. This promitotic signaling was shown to involve PLC signaling pathway (Nicot and DiCicco-Bloom, 2001). PAC1-hop1 was also shown to promote sympathetic neurons survival following growth factor withdrawal (May et al., 2010).

In conjunction with the abovementioned, PACAP may possess therapeutic potential for neurodegenerative pathologies, such as Parkinson's and Alzheimer's disease (AD). PACAP is enriched in rat mesencephalic dopaminergic neurons and protects them from neurotoxin-induced death (Reglodi et al., 2004). PACAP was shown to be downregulated in several mouse models for $\mathrm{AD}$ as well as in the human temporal cortex of $\mathrm{AD}$ patients (Kojro et al., 2006; Rat et al., 2011; Postina, 2012). Amyloidogenic processing of the amyloid precursor protein (APP) to $\alpha \beta$-peptides is responsible for the development of AD. However, non-amyloidogenic APP processing pathway results in the $\alpha$-secretase-dependent cleavage within the $\alpha \beta$-peptide region, preventing AD pathology. Continual PACAP and PAC1 activation resulted also in a feed-forward autocrine elevation of both PACAP and PAC1 in mice that may further facilitate non-amyloidogenic APP cleavage. $\alpha$-secretase activation was shown to be regulated by ERK1 and ERK 2 and PI-3 kinase, suggesting that PAC1hop1 is the most efficient isoform with regard to the activation of these downstream PLC effectors (Kojro et al., 2006; Rat et al., 2011; Postina, 2012). It remains to be determined whether specific PAC1 splice variants are involved in these neuroprotective activities.

\section{NEUROSECRETION AND NEUROTRANSMISSION}

Pituitary AC-activating polypeptide was shown to elicit catecholamine synthesis and release. Expression of PAC1-hop1 in bovine chromaffin NG108-15 cell line, which lacks endogenous PAC1 receptors, induces the release of norepinephrine via a $\mathrm{Ca}^{2+}$ influx-dependent mechanism (Mustafa et al., 2007). Transfected PAC1-hop1 triggers sustained catecholamine secretion by regulating $\mathrm{Ca}^{2+}$ levels through both ER and $\mathrm{EC} \mathrm{Ca}^{2+}$ channels (Mustafa et al., 2010; Smith and Eiden, 2012). Moreover, acute and longterm met-enkephalin secretion and enkephalin biosynthesis were attributed to bovine chromaffin cells upon PAC1-hop1-mediated activation of L-type $\mathrm{Ca}^{2+}$ channels. This implies a role of hop1 splice cassette in regulating neuroendocrine secretion. SCG sympathetic neurons were shown to predominantly express the PAC1hop1 splice isoform and PACAP stimulates neuropeptide $Y$ release in these neurons via a mechanism involving both AC and PLC $\beta$ (Braas and May, 1999).

\section{ROLE OF PAC1 SPLICE ISOFORMS IN BODY HOMEOSTASIS}

PAC1 is implicated in the regulation of homeostatic processes, including food and liquid consumption (Nomura et al., 1997; Mounien et al., 2006, 2009), sleep (Hannibal and Fahrenkrug, 2004), stress (Pilzer and Gozes, 2006b; Amir-Zilberstein et al., 2012), locomotion (Vaudry et al., 2000), memory and learning activities (Dong et al., 2010; Andero and Ressler, 2012; Holighaus et al., 2012), and circadian functions (Ajpru et al., 2002; Hannibal and Fahrenkrug, 2004). Recent studies have indicated that at least some of these activities are modulated by alternative splicing of PAC1 (Ajpru et al., 2002; Hannibal and Fahrenkrug, 2004; Pilzer and Gozes, 2006b; Holighaus et al., 2011, 2012; Amir-Zilberstein et al., 2012).

Pituitary AC-activating polypeptide/PAC1 signaling was recently implicated in abnormal stress responses underlying posttraumatic stress disorder (PTSD) pathology (Ressler et al., 2011; Andero and Ressler, 2012; Hauger et al., 2012). PACAP38 levels in females were strongly associated with PTSD symptoms. Ressler et al. and May et al. (2010) found that a single nucleotide polymorphism (SNP), rs2267735 in the PAC1 gene is correlated with PTSD in a gender-specific estrogen-dependent manner. This SNP, which resides in the putative estrogen response element within PAC1's promoter/enhancer is associated with sexdependent PTSD, fear discrimination, PAC1 mRNA expression, and methylation of PAC1. Using mouse models, these authors showed that PAC1 mRNA was induced by fear conditioning or estrogen hormone replacement in the bed nucleus of stria terminalis (BNST), which is a component of the extended amygdala involved in fear- and anxiety-like responses.

In connection to the above, steroid-induced changes in PAC1 splice isoforms were demonstrated in the case of PAC1-hop2 (Apostolakis et al., 2005). PAC1-hop2 and the N-terminal PAC1short splice variants were detected in the hypothalamic ventromedial nucleus (VMN) upon estradiol or dual estradiol/progesterone 
treatment. The ratio of PAC1-hop2 mRNA to other PAC1 variants in VMN depends on steroid application, implying its importance for cumulative PAC1 isoforms expression and hence signaling properties. PACAP-induced sexual/mating behavior in female rats was dependent on progesterone receptor in the VMN. Estradiol stimulates synthesis of progesterone, which in turn facilitates PACAP synthesis and activation of PAC1-short and -hop2 signaling critical for the induction of animal sexual receptivity.

PAC1 signaling is known to be required for physiological stress response as activation of PAC1 by PACAP is required for stress-induced $\mathrm{CRH}$ transcription in vivo and in vitro (Agarwal et al., 2005; Kageyama et al., 2007; Hammack et al., 2010b; Stroth and Eiden, 2010; Tsukiyama et al., 2011). The above studies suggest that PAC1 splice variants and their relative expression ratio might be involved in the regulation of body homeostasis including physiological responses to stressor challenges. A recent study performed in our lab, employed various stress paradigms in mouse and zebrafish to demonstrate that activation and termination of CRH transcription caused by stressful stimuli is regulated by an interrelationship of PAC1-null and hop1 isoforms (Amir-Zilberstein et al., 2012). Thus, the generation of PAC1-hop1 by alternative splicing leads to the termination of $\mathrm{CRH}$ transcription, normal activation of the hypothalamicpituitary-adrenal axis, and adaptive anxiety-like behavior (AmirZilberstein et al., 2012). We therefore suggested that alternative splicing of the hop1-cassette serves as an ON/OFF stress switch (Figure 6).

PAC1 rs2267735 gene polymorphism is also associated with increased dark-enhanced startle (DES) in adult females but not males with PTSD (Ressler et al., 2011). Moreover, children of abused mothers show elevated DES and the same PAC1 gene polymorphism associated with PTSD risk in adult females is also associated with increased DES in these children (Jovanovic et al., 2011,2012). Notably, zebrafish larvae show a strong aversion to the dark side of a two-compartment light/dark arena and this place preference can be mitigated by anxiolytic drugs, such as Diazepam, indicating that this assay measures an anxiety-like behavior (Steenbergen et al., 2011; Schnorr et al., 2012). We found that during the recovery phase that follows a stressful challenge (osmotic shock), wild type larvae decrease their dark-avoidance time, a phenotype indicative of decreased stress-related anxiety, while larvae with depleted PACla-hop1 display delayed dark-avoidance recovery (Amir-Zilberstein et al., 2012). Thus, the delayed behavioral response of PACla-hop1-depleted embryos correlates with their respective failure to terminate crh and cortisol levels following stressors.

\section{CONCLUSION}

Alternative splicing is a major gene regulatory process involving cis- and trans-acting factors. PAC1 signaling controls a variety of cellular and physiological responses, such as differentiation, proliferation, cell cycle regulation, neurotransmitter, and hormone release and adaptation to stressful challenges. The PAC1 gene encompasses a relatively long genomic region, which consists of up to 18 exons and contains many putative splicing

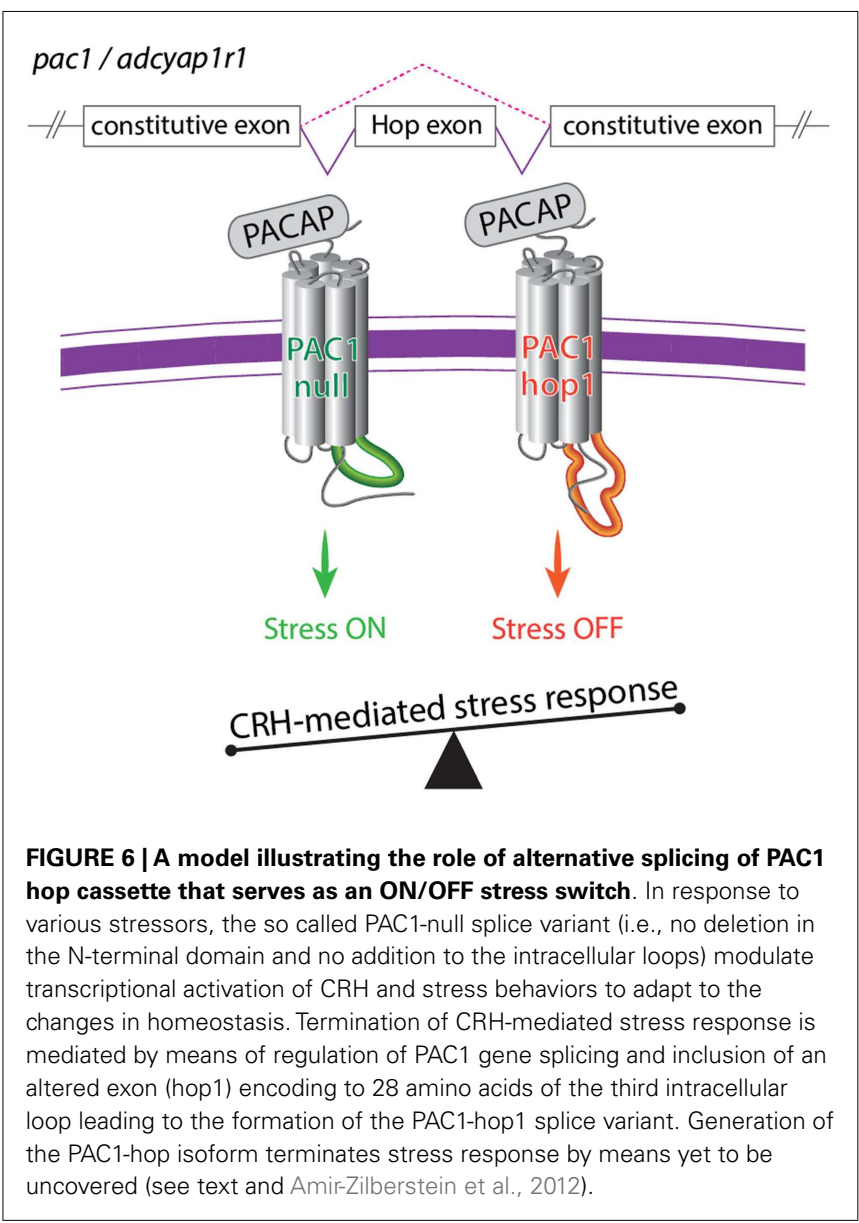

factors recognition sites that might be activated during different phases of neuronal activation. PAC1 receptor signaling can be fine-tuned by the generation of a set of alternatively spliced variants produced in a spatio-temporal manner. Splicingdependent alterations in PAC1 protein domains modify its ligand binding and signaling properties leading to a range of cellular activities. Although the physiological function(s) of the vast majority of the alternatively spliced PAC1 gene products is still unknown, recent studies have implicated certain PAC1 splice variants in the regulation of homeostatic processes such as adaptation to stressful challenges. In view of the recent association of PAC1 with PTSD risk, the regulation of PAC1 splicing and its underlying physiological outcomes might prove to be relevant to the etiology of some neurological and psychiatric disorders.

\section{ACKNOWLEDGMENTS}

We thank Shifra Ben-Or for PAC1 gene structure and phylogenetic analyses and Danielle Sabah-Israel, Jacob Biran, and Michael Gliksberg for comments on the manuscript. The research in the Levkowitz lab is supported by the Simons Foundation Autism Research Initiative (SFARI); Israel Science Foundation; Kirk Center for Childhood Cancer and Immunological Disorders; The Krenter Institute and Estate of Lore Lennon. 


\section{REFERENCES}

Abu-Hamdan, M. D., Drescher, M. J., Ramakrishnan, N. A., Khan, K. M., Toma, V. S., Hatfield, J. S., et al. (2006). Pituitary adenylyl cyclase-activating polypeptide (PACAP) and its receptor (PAC1$\mathrm{R}$ ) in the cochlea: evidence for specific transcript expression of PAC1$\mathrm{R}$ splice variants in rat microdissected cochlear subfractions. Neuroscience 140, 147-161.

Acampora, D., Postiglione, M. P., Avantaggiato, V., Di Bonito, M., Vaccarino, F. M., Michaud, J., et al. (1999). Progressive impairment of developing neuroendocrine cell lineages in the hypothalamus of mice lacking the Orthopedia gene. Genes Dev. 13, 2787-2800.

Agarwal, A., Halvorson, L. M., and Legradi, G. (2005). Pituitary adenylate cyclase-activating polypeptide (PACAP) mimics neuroendocrine and behavioral manifestations of stress: evidence for PKA-mediated expression of the corticotropinreleasing hormone $(\mathrm{CRH})$ gene. Brain Res. Mol. Brain Res. 138, 45-57.

Ahren, B. (2008). Role of pituitary adenylate cyclase-activating polypeptide in the pancreatic endocrine system. Ann. N. Y. Acad. Sci. 1144, 28-35.

Aino, H., Hashimoto, H., Ogawa, N., Nishino, A., Yamamoto, K., Nogi, H., et al. (1995). Structure of the gene encoding the mouse pituitary adenylate cyclase-activating polypeptide receptor. Gene 164, 301-304.

Ajpru, S., McArthur, A. J., Piggins, H. D., and Sugden, D. (2002). Identification of $\mathrm{PACl}$ receptor isoform mRNAs by real-time PCR in rat suprachiasmatic nucleus. Brain Res. Mol. Brain Res. 105, 29-37.

Alexandre, D., Vaudry, H., Grumolato, L., Turquier, V., Fournier, A., Jegou, S., et al. (2002). Novel splice variants of type I pituitary adenylate cyclaseactivating polypeptide receptor in frog exhibit altered adenylate cyclase stimulation and differential relative abundance. Endocrinology 143, 2680-2692.

Allemand, E., Guil, S., Myers, M., Moscat, J., Caceres, J. F., and Krainer, A. R. (2005). Regulation of heterogenous nuclear ribonucleoprotein Al transport by phosphorylation in cells stressed by osmotic shock. Proc. Natl. Acad. Sci. U.S.A. 102, 3605-3610.

Amir-Zilberstein, L., Blechman, J., Sztainberg, Y., Norton, W. H., Reuveny, A., Borodovsky, N., et al. (2012). Homeodomain protein otp and activity-dependent splicing modulate neuronal adaptation to stress. Neuron 73, 279-291.

An, P., and Grabowski, P. J. (2007). Exon silencing by UAGG motifs in response to neuronal excitation. PLoS Biol. 5:e36. doi:10.1371/journal.pbio.0050036

Andero, R., and Ressler, K. J. (2012). Fear extinction and BDNF: translating animal models of PTSD to the clinic. Genes Brain Behav. 11, 503-512.

Apostolakis, E. M., Riherd, D. N., and O'Malley, B. W. (2005). PAC1 receptors mediate pituitary adenylate cyclase-activating polypeptideand progesterone-facilitated receptivity in female rats. Mol. Endocrinol. 19, 2798-2811.

Arimura, A. (1998). Perspectives on pituitary adenylate cyclase activating polypeptide (PACAP) in the neuroendocrine, endocrine, and nervous systems. Jpn. J. Physiol. 48, 301-331.

Ashur-Fabian, O., Giladi, E., Brenneman, D. E., and Gozes, I. (1997). Identification of VIP/PACAP receptors on rat astrocytes using antisense oligodeoxynucleotides. J. Mol. Neurosci. 9, 211-222.

Baxter, P. S., Martel, M. A., McMahon, A., Kind, P. C., and Hardingham, G. E. (2011). Pituitary adenylate cyclase-activating peptide induces long-lasting neuroprotection through the induction of activity-dependent signaling via the cyclic AMP response elementbinding protein-regulated transcription co-activator 1. J. Neurochem. 118, 365-378.

Betke, K. M., Wells, C. A., and Hamm, H. E. (2012). GPCR mediated regulation of synaptic transmission. Prog. Neurobiol. 96, 304-321.

Bjarnadottir, T. K., Gloriam, D. E., Hellstrand, S. H., Kristiansson, H., Fredriksson, R., and Schioth, H. B. (2006). Comprehensive repertoire and phylogenetic analysis of the $G$ protein-coupled receptors in human and mouse. Genomics 88, 263-273.

Black, D. L. (2003). Mechanisms of alternative pre-messenger RNA splicing. Annu. Rev. Biochem. 72, 291-336.

Blechman, J., Borodovsky, N., Eisenberg, M., Nabel-Rosen, H., Grimm, J., and Levkowitz, G. (2007). Specification of hypothalamic neurons by dual regulation of the homeodomain protein Orthopedia. Development 134, 4417-4426.

Botia, B., Basille, M., Allais, A., Raoult, E., Falluel-Morel, A., Galas, L., et al. (2007). Neurotrophic effects of
PACAP in the cerebellar cortex. Peptides 28, 1746-1752.

Braas, K. M., and May, V. (1996). Pituitary adenylate cyclase-activating polypeptides, PACAP-38 and PACAP-27, regulation of sympathetic neuron catecholamine, and neuropeptide $\mathrm{Y}$ expression through activation of type I PACAP/VIP receptor isoforms. Ann. N. Y. Acad. Sci. 805, 204-216; discussion 217-208.

Braas, K. M., and May, V. (1999). Pituitary adenylate cyclase-activating polypeptides directly stimulate sympathetic neuron neuropeptide $\mathrm{Y}$ release through $\mathrm{PAC}(1)$ receptor isoform activation of specific intracellular signaling pathways. J. Biol. Chem. 274, 27702-27710.

Buljan, M., Chalancon, G., Eustermann, S., Wagner, G. P., Fuxreiter, M., Bateman, A., et al. (2012). Tissue-specific splicing of disordered segments that embed binding motifs rewires protein interaction networks. Mol. Cell 46, 871-883.

Cardoso, J. C., De Vet, E. C., Louro, B., Elgar, G., Clark, M. S., and Power, D. M. (2007). Persistence of duplicated PAC1 receptors in the teleost, Sparus auratus. BMC Evol. Biol. 7:221. doi:10.1186/1471-2148-7-221

Castel, H., Vaudry, D., Mei, Y. A., Lefebvre, T., Basille, M., Desrues, L., et al. (2006). The delayed rectifier channel current IK plays a key role in the control of programmed cell death by PACAP and ethanol in cerebellar granule neurons. Ann. N. Y. Acad. Sci. 1070, 173-179.

Cavallaro, S., D'Agata, V., Guardabasso, V., Travali, S., Stivala, F., and Canonico, P. L. (1995). Differentiation induces pituitary adenylate cyclase-activating polypeptide receptor expression in PC-12 cells. Mol. Pharmacol. 48, 56-62.

Chafai, M., Basille, M., Galas, L., Rostene, W., Gressens, P., Vaudry, H., Gonzalez, B. J., et al. (2011). Pituitary adenylate cyclase-activating polypeptide and vasoactive intestinal polypeptide promote the genesis of calcium currents in differentiating mouse embryonic stem cells. Neuroscience 199, 103-115.

Chatterjee, T. K., Liu, X., Davisson, R. L., and Fisher, R. A. (1997). Genomic organization of the rat pituitary adenylate cyclaseactivating polypeptide receptor gene. Alternative splicing within the 5'-untranslated region. J. Biol. Chem. 272, 12122-12131.

Chatterjee, T. K., Sharma, R. V., and Fisher, R. A. (1996). Molecular cloning of a novel variant of the pituitary adenylate cyclaseactivating polypeptide (PACAP) receptor that stimulates calcium influx by activation of L-type calcium channels. J. Biol. Chem. 271, 32226-32232.

Clapham, D. E. (2007). Calcium signaling. Cell 131, 1047-1058.

Costa, L., Santangelo, F., Volsi, G. L., and Ciranna, L. (2009). Modulation of AMPA receptor-mediated ion current by pituitary adenylate cyclase-activating polypeptide (PACAP) in CA1 pyramidal neurons from rat hippocampus. Hippocampus 19, 99-109.

Couvineau, A., and Laburthe, M. (2012). The family B1 GPCR: structural aspects and interaction with accessory proteins. Curr. Drug Targets 13, 103-115.

D'Agata, V., Cavallaro, S., Stivala, F., Travali, S., and Canonico, P. L. (1996). Tissue-specific and developmental expression of pituitary adenylate cyclase-activating polypeptide (PACAP) receptors in rat brain. Eur. J. Neurosci. 8, 310-318.

Daniel, P. B., Kieffer, T. J., Leech, C. A., and Habener, J. F. (2001). Novel alternatively spliced exon in the extracellular ligand-binding domain of the pituitary adenylate cyclase-activating polypeptide (PACAP) type 1 receptor (PAC1R) selectively increases ligand affinity and alters signal transduction coupling during spermatogenesis. $J$. Biol. Chem. 276, 12938-12944.

Dautzenberg, F. M., Mevenkamp, G., Wille, S., and Hauger, R. L. (1999). N-terminal splice variants of the type I PACAP receptor: isolation, characterization and ligand binding/selectivity determinants. J. Neuroendocrinol. 11, 941-949.

Dejda, A., Jozwiak-Bebenista, M., and Nowak, J. Z. (2006). PACAP, VIP, and PHI: effects on AC-, PLC-, and PLD-driven signaling systems in the primary glial cell cultures. Ann. N. Y. Acad. Sci. 1070, 220-225.

DiCicco-Bloom, E., Deutsch, P. J., Maltzman, J., Zhang, J., Pintar, J. E., Zheng, J., et al. (2000) Autocrine expression and ontogenetic functions of the PACAP ligand/receptor system during sympathetic development. Dev. Biol. 219, 197-213.

Dickson, L., and Finlayson, K. (2009). VPAC and PAC receptors: from ligands to function. Pharmacol. Ther. 121, 294-316.

Donev, R., Newall, A., Thome, J., and Sheer, D. (2007). A role for SC35 and hnRNPAl in the determination of 
amyloid precursor protein isoforms. Mol. Psychiatry 12, 681-690.

Dong, M. Q., Pinon, D. I., and Miller, L. J. (2005). Insights into the structure and molecular basis of ligand docking to the G proteincoupled secretin receptor using charge-modified amino-terminal agonist probes. Mol. Endocrinol. 19, 1821-1836.

Dong, Y. X., Fukuchi, M., Inoue, M., Takasaki, I., Tabuchi, A., Wu, C. F., et al. (2010). Pituitary adenylate cyclase-activating polypeptide (PACAP) is an upstream regulator of prodynorphin mRNA expression in neurons. Neurosci. Lett. 484, 174-177.

Emery, A. C., and Eiden, L. E. (2012). Signaling through the neuropeptide GPCR PAC1 induces neuritogenesis via a single linear cAMPand ERK-dependent pathway using a novel cAMP sensor. FASEB J. 26, 3199-3211.

Falktoft, B., Georg, B., and Fahrenkrug, J. (2009). Signaling pathways in PACAP regulation of VIP gene expression in human neuroblastoma cells. Neuropeptides 43, 387-396.

Falluel-Morel, A., Vaudry, D., Aubert, N., Galas, L., Benard, M., Basille, M., et al. (2006). PACAP and ceramides exert opposite effects on migration, neurite outgrowth, and cytoskeleton remodeling. Ann. N. Y. Acad. Sci. 1070, 265-270.

Fernandes, A. M., Fero, K., Arrenberg, A. B., Bergeron, S. A., Driever, W., and Burgess, H. A. (2012). Deep Brain photoreceptors control light-seeking behavior in zebrafish larvae. Curr. Biol. 22, 2042-2047.

Fila, T., Trazzi, S., Crochemore, C., Bartesaghi, R., and Ciani, E. (2009). Lot1 is a key element of the pituitary adenylate cyclase-activating polypeptide (PACAP)/cyclic AMP pathway that negatively regulates neuronal precursor proliferation. $J$. Biol. Chem. 284, 15325-15338.

Fradinger, E. A., Tello, J. A., Rivier, J. E., and Sherwood, N. M. (2005). Characterization of four receptor cDNAs: PAC1, VPAC1, a novel PAC1 and a partial GHRH in zebrafish. Mol. Cell. Endocrinol. 231, 49-63.

Frooninckx, L., Van Rompay, L., Temmerman, L., Van Sinay, E., Beets, I., Janssen, T., et al. (2012). Neuropeptide GPCRs in C. elegans. Front. Endocrinol. 3:167. doi:10.3389/fendo.2012.00167

Furness, S. G., Wootten, D., Christopoulos, A., and Sexton, P. M. (2012). Consequences of splice variation on Secretin family G protein-coupled receptor function. Br. J. Pharmacol. $166,98-109$.

Gerdin, M. J., and Eiden, L. E. (2007). Regulation of PC12 cell differentiation by cAMP signaling to ERK independent of PKA: do all the connections add up? Sci. STKE 2007, e15

Germano, P. M., Le, S. V., Oh, D. S., Fan, R., Lieu, S., Siu, A., et al. (2004). Differential coupling of the PAC1 SV1 splice variant on human colonic tumors to the activation of intracellular cAMP but not intracellular $\mathrm{Ca} 2+$ does not activate tumor proliferation. J. Mol. Neurosci. 22, 83-92.

Germano, P. M., Lieu, S. N., Xue, J., Cooke, H. J., Christofi, F. L., Lu, Y., et al. (2009). PACAP induces signaling and stimulation of 5-hydroxytryptamine release and growth in neuroendocrine tumor cells. J. Mol. Neurosci. 39, 391-401.

Ghosh, A., Ginty, D. D., Bading, H., and Greenberg, M. E. (1994). Calcium regulation of gene-expression in neuronal cells. J. Neurobiol. 25, 294-303.

Gillard, E. R., Leon-Olea, M., MucioRamirez, S., Coburn, C. G., SanchezIslas, E., De Leon, A., et al. (2006). A novel role for endogenous pituitary adenylate cyclase activating polypeptide in the magnocellular neuroendocrine system. Endocrinology 147, 791-803.

Girard, B. M., Keller, E. T., Schutz, K. C., May, V., and Braas, K. M. (2004). Pituitary adenylate cyclase activating polypeptide and $\mathrm{PACl}$ receptor signaling increase Homer la expression in central and peripheral neurons. Regul. Pept. 123, 107-116.

Gomariz, R. P., Juarranz, Y., Abad, C., Arranz, A., Leceta, J., and Martinez, C. (2006). VIP-PACAP system in immunity - new insights for multitarget therapy. Ann. N. Y. Acad. Sci. 1070, 51-74.

Grammatopoulos, D. K., Dai, Y., Randeva, H. S., Levine, M. A., Karteris, E., Easton, A. J., et al. (1999). A novel spliced variant of the type 1 corticotropin-releasing hormone receptor with a deletion in the seventh transmembrane domain present in the human pregnant term myometrium and fetal membranes. Mol. Endocrinol. 13, 2189-2202.

Grimaldi, M., and Cavallaro, S. (1999). Functional and molecular diversity of PACAP/VIP receptors in cortical neurons and type I astrocytes. Eur. J. Neurosci. 11, 2767-2772.

Grumolato, L., Louiset, E., Alexandre, D., Ait-Ali, D., Turquier, V., Fournier, A., et al. (2003). PACAP and NGF regulate common and distinct traits of the sympathoadrenal lineage: effects on electrical properties, gene markers and transcription factors in differentiating PC12 cells. Eur. J. Neurosci. 17, 71-82.

Hammack, S. E., Roman, C. W., Lezak, K. R., Kocho-Shellenberg, M., Grimmig, B., Falls, W. A., et al. (2010a). Roles for pituitary adenylate cyclaseactivating peptide (PACAP) expression and signaling in the bed nucleus of the stria terminalis (BNST) in mediating the behavioral consequences of chronic stress. J. Mol. Neurosci. 42, 327-340.

Hammack, S. E., Roman, C. W., Lezak, K. R., Kocho-Shellenberg, M., Grimmig, B., Falls, W. A., et al. (2010b) Roles for pituitary adenylate cyclaseactivating peptide (PACAP) expression and signaling in the bed nucleus of the stria terminalis (BNST) in mediating the behavioral consequences of chronic stress. J. Mol. Neurosci. 34, 833-843.

Hannibal, J., and Fahrenkrug, J. (2004). Target areas innervated by PACAPimmunoreactive retinal ganglion cells. Cell Tissue Res. 316, 99-113.

Hansson, E., Westerlund, A., Bjorklund, U., and Ronnback, L. (2009). PACAP attenuates 5-HT, histamine, and ATP-evoked $\mathrm{Ca} 2+$ transients in astrocytes. Neuroreport 20, 957-962.

Harikumar, K. G., Morfis, M. M., Sexton, P. M., and Miller, L. J. (2008). Pattern of intra-family heterooligomerization involving the Gprotein-coupled secretin receptor. $J$. Mol. Neurosci. 36, 279-285.

Harmar, A. J., Fahrenkrug, J., Gozes, I., Laburthe, M., May, V., Pisegna, J. R., et al. (2012). Pharmacology and functions of receptors for vasoactive intestinal peptide and pituitary adenylate cyclase-activating polypeptide: IUPHAR review $1 . \mathrm{Br}$. J. Pharmacol. 166, 4-17.

Hashimoto, H., Kunugi, A., Arakawa, N., Shintani, N., Fujita, T., Kasai, A., et al. (2003). Possible involvement of a cyclic AMP-dependent mechanism in PACAP-induced proliferation and ERK activation in astrocytes. Biochem. Biophys. Res. Commun. 311, 337-343.

Hauger, R. L., Olivares-Reyes, J. A., Dautzenberg, F. M., Lohr, J. B., Braun, S., and Oakley, R. H. (2012). Molecular and cell signaling targets for PTSD pathophysiology and pharmacotherapy. Neuropharmacology 62, 705-714.

Holighaus, Y., Mustafa, T., and Eiden, L. E. (2011). PAC1hop, null and hip receptors mediate differential signaling through cyclic AMP and calcium leading to splice variantspecific gene induction in neural cells. Peptides 32, 1647-1655.

Holighaus, Y., Weihe, E., and Eiden, L. E. (2012). STC1 induction by PACAP is mediated through cAMP and ERK $1 / 2$ but not PKA in cultured cortical neurons. J. Mol. Neurosci. 46, 75-87.

Hoyer, D., and Bartfai, T. (2012). Neuropeptides and neuropeptide receptors: drug targets, and peptide and non-peptide ligands: a tribute to Prof. Dieter Seebach. Chem. Biodivers. 9, 2367-2387.

Jafurulla, M., and Chattopadhyay, A. (2013). Membrane lipids in the function of serotonin and adrenergic receptors. Curr. Med. Chem. 20, 47-55.

Jaillon, O., Bouhouche, K., Gout, J. F., Aury, J. M., Noel, B., Saudemont, B., et al. (2008). Translational control of intron splicing in eukaryotes. Nature 451, 359-362.

Jamen, F., Alonso, G., Shibuya, I., Widmer, H., Vacher, C. M., Calas, A. et al. (2003). Impaired somatodendritic responses to pituitary adenylate cyclase-activating polypeptide (PACAP) of supraoptic neurones in PACAP type I-receptor deficient mice. J. Neuroendocrinol. 15, 871-881.

Jamen, F., Puech, R., Bockaert, J., Brabet, P., and Bertrand, G. (2002). Pituitary adenylate cyclase-activating polypeptide receptors mediating insulin secretion in rodent pancreatic islets are coupled to adenylate cyclase but not to PLC. Endocrinology 143, 1253-1259.

Jolivel, V., Basille, M., Aubert, N., De Jouffrey, S., Ancian, P., Le Bigot, J. F., et al. (2009). Distribution and functional characterization of pituitary adenylate cyclaseactivating polypeptide receptors in the brain of non-human primates. Neuroscience 160, 434-451.

Journot, L., Spengler, D., Pantaloni, C. Dumuis, A., Sebben, M., and Bockaert, J. (1994). The PACAP receptor: generation by alternative splicing of functional diversity among $G$ protein-coupled receptors in nerve cells. Semin. Cell Biol. 5, 263-272.

Journot, L., Waeber, C., Pantaloni, C., Holsboer, F., Seeburg, P. H., Bockaert, J., et al. (1995). Differential signal transduction by six splice variants of the pituitary adenylate cyclase-activating peptide (PACAP) receptor. Biochem. Soc. Trans. 23, 133-137.

Jovanovic, T., Norrholm, S. D., Davis, J., Mercer, K. B., Almli, L., Nelson, A., et al. (2012). PAC1 
receptor (ADCYAP1R1) genotype is associated with dark-enhanced startle in children. Mol. Psychiatry. doi:10.1038/mp.2012.98. [Epub ahead of print].

Jovanovic, T., Smith, A., Kamkwalala, A., Poole, J., Samples, T., Norrholm, S. D., et al. (2011). Physiological markers of anxiety are increased in children of abused mothers. J. Child. Psychol. Psychiatry 52, 844-852.

Kageyama, K., Hanada, K., Iwasaki, Y., Sakihara, S., Nigawara, T., Kasckow, J., et al. (2007). Pituitary adenylate cyclase-activating polypeptide stimulates corticotropin-releasing factor, vasopressin and interleukin- 6 gene transcription in hypothalamic $4 \mathrm{~B}$ cells. J. Endocrinol. 195, 199-211.

Kanasaki, H., Mutiara, S., Oride, A., Purwana, I. N., and Miyazaki, K. (2009). Pulse frequency-dependent gonadotropin gene expression by adenylate cyclase-activating polypeptide 1 in perifused mouse pituitary gonadotroph LbetaT2 cells. Biol. Reprod. 81, 465-472.

Kojro, E., Postina, R., Buro, C., Meiringer, C., Gehrig-Burger, K., and Fahrenholz, F. (2006). The neuropeptide PACAP promotes the alpha-secretase pathway for processing the Alzheimer amyloid precursor protein. FASEB J. 20, 512-514.

Lakk, M., Szabo, B., Volgyi, B., Gabriel, R., and Denes, V. (2012). Development-related splicing regulates pituitary adenylate cyclase-activating polypeptide (PACAP) receptors in the retina. Invest. Ophthalmol. Vis. Sci. 53, 7825-7832.

Lee, H. W., Hahm, S. H., Hsu, C. M., and Eiden, L. E. (1999). Pituitary adenylate cyclase-activating polypeptide regulation of vasoactive intestinal polypeptide transcription requires $\mathrm{Ca} 2+$ influx and activation of the serine/threonine phosphatase calcineurin. J. Neurochem. 73, 1769-1772.

Lee, J. A., Tang, Z. Z., and Black, D. L. (2009). An inducible change in Fox-1/A2BP1 splicing modulates the alternative splicing of downstream neuronal target exons. Genes Dev. 23, 2284-2293.

Lee, J. A., Xing, Y., Nguyen, D., Xie, J., Lee, C. J., and Black, D. L. (2007). Depolarization and CaM kinase IV modulate NMDA receptor splicing through two essential RNA elements. PLoS Biol. 5:e40. doi:10.1371/journal.pbio.0050040

Lefkowitz, R. J. (2007). Seven transmembrane receptors: something old, something new. Acta Physiol. (Oxf.) 190, 9-19.
Llansola, M., Sanchez-Perez, A. M., Montoliu, C., and Felipo, V. (2004). Modulation of NMDA receptor function by cyclic AMP in cerebellar neurones in culture. J. Neurochem. 91, 591-599.

Lu, N., Zhou, R., and DiCicco-Bloom, E. (1998). Opposing mitogenic regulation by PACAP in sympathetic and cerebral cortical precursors correlates with differential expression of PACAP receptor (PAC1-R) isoforms. J. Neurosci. Res. 53, 651-662.

Lugo, J. M., Tafalla, C., Leceta, J., Gomariz, R. P., and Estrada, M. P. (2011). Differential expression pattern of pituitary adenylate cyclase-activating polypeptide (PACAP) alternative splicing variants and its receptors in the immune system of rainbow trout (Oncorhynchus mykiss). Fish Shellfish Immunol. 30, 734-738.

Lutz, E. M., Ronaldson, E., Shaw, P., Johnson, M. S., Holland, P. J., and Mitchell, R. (2006). Characterization of novel splice variants of the PAC1 receptor in human neuroblastoma cells: consequences for signaling by VIP and PACAP. Mol. Cell. Neurosci. 31, 193-209.

Machluf, Y., Gutnick, A., and Levkowitz, G. (2011). Development of the zebrafish hypothalamus. Ann. N. Y. Acad. Sci. 1220, 93-105.

Magalhaes, A. C., Dunn, H., and Ferguson, S. S. (2012). Regulation of GPCR activity, trafficking and localization by GPCR-interacting proteins. Br. J. Pharmacol. 165, 1717-1736.

Mahata, M., Zhang, K., Gayen, J. R., Nandi, S., Brar, B. K., Ghosh, S., et al. (2011). Catecholamine biosynthesis and secretion: physiological and pharmacological effects of secretin. Cell Tissue Res. 345, 87-102.

Makhlouf, G. M., and Murthy, K. S. (1997). Signal transduction in gastrointestinal smooth muscle. Cell. Signal. 9, 269-276.

Markovic, D., and Grammatopoulos, D. K. (2009). Focus on the splicing of secretin GPCRs transmembranedomain 7. Trends Biochem. Sci. 34, 443-452.

Markovic, D., Lehnert, H., Levine, M. A., and Grammatopoulos, D. K. (2008). Structural determinants critical for localization and signaling within the seventh transmembrane domain of the type 1 corticotropin releasing hormone receptor: lessons from the receptor variant R1d. Mol. Endocrinol. 22, 2505-2519.

Masmoudi, O., Gandolfo, P., Leprince, J., Vaudry, D., Fournier, A., Patte-Mensah, C., et al. (2003).
Pituitary adenylate cyclaseactivating polypeptide (PACAP) stimulates endozepine release from cultured rat astrocytes via a PKAdependent mechanism. FASEB J. 17, 17-27.

Masmoudi-Kouki, O., Gandolfo, P., Leprince, J., Vaudry, D., Pelletier, G., Fournier, A., et al. (2006). PACAP stimulates biosynthesis and release of endozepines from rat astrocytes. Ann. N. Y. Acad. Sci. 1070, 411-416.

Maturana, A., Van Haasteren, G., Piuz, I., Castelbou, C., Demaurex, N., and Schlegel, W. (2002). Spontaneous calcium oscillations control c-fos transcription via the serum response element in neuroendocrine cells. $J$. Biol. Chem. 277, 39713-39721.

Maurice, P., Guillaume, J. L., BenleulmiChaachoua, A., Daulat, A. M., Kamal M., and Jockers, R. (2011). GPCRinteracting proteins, major players of GPCR function. Adv. Pharmacol. $62,349-380$.

May, V., Lutz, E., MacKenzie, C., Schutz, K. C., Dozark, K., and Braas, K. M. (2010). Pituitary adenylate cyclase-activating polypeptide (PACAP)/PAC1HOP1 receptor activation coordinates multiple neurotrophic signaling pathways: Akt activation through phosphatidylinositol 3-kinase gamma and vesicle endocytosis for neuronal survival. $J$. Biol. Chem. 285, 9749-9761.

McCulloch, D. A., Lutz, E. M., Johnson, M. S., Robertson, D. N., MacKenzie, C. J., Holland, P. J., et al. (2001). ADP-ribosylation factor-dependent phospholipase D activation by VPAC receptors and a $\mathrm{PAC}(1)$ receptor splice variant. Mol. Pharmacol. 59, 1523-1532.

McCulloch, D. A., MacKenzie, C. J., Johnson, M. S., Robertson, D. N., Holland, P. J., Ronaldson, E., et al. (2002). Additional signals from VPAC/PAC family receptors. Biochem. Soc. Trans. 30, 441-446.

Mei, Y. A., Vaudry, D., Basille, M., Castel, H., Fournier, A., Vaudry, H., et al. (2004). PACAP inhibits delayed rectifier potassium current via a cAMP/PKA transduction pathway: evidence for the involvement of I-K in the anti-apoptotic action of PACAP. Eur. J. Neurosci. 19, 1446-1458.

Milligan, G., and Kostenis, E. (2006). Heterotrimeric G-proteins: a short history. Br. J. Pharmacol. 147(Suppl. 1), S46-S55.

Miyata, A., Arimura, A., Dahl, R. R., Minamino, N., Uehara, A., Jiang, L., et al. (1989). Isolation of a novel 38 residue-hypothalamic polypeptide which stimulates adenylate cyclase in pituitary cells. Biochem. Biophys. Res. Commun. 164, 567-574.

Mizuno, N., and Itoh, H. (2009). Functions and regulatory mechanisms of Gq-signaling pathways. Neurosignals 17, 42-54.

Molnar, L., Pollak, E., Boros, A., Shioda, S., Nakajo, S., Tamas, A., et al. (2008). PAC1 receptor localization in a model nervous system: light and electron microscopic immunocytochemistry on the earthworm ventral nerve cord ganglia. Regul. Pept. 145, 96-104.

Monaghan, T. K., Pou, C., MacKenzie, C. J., Plevin, R., and Lutz, E. M. (2008). Neurotrophic actions of PACAP-38 and LIF on human neuroblastoma SH-SY5Y cells. J. Mol. Neurosci. 36 45-56.

Morfis, M., Christopoulos, A., and Sexton, P. M. (2003). RAMPs: 5 years on, where to now? Trends Pharmacol. Sci. 24, 596-601.

Mounien, L., Bizet, P., Boutelet, I., Gourcerol, G., Fournier, A., Vaudry, H., et al. (2006). Pituitary adenylate cyclase-activating polypeptide directly modulates the activity of proopiomelanocortin neurons in the rat arcuate nucleus. Neuroscience 143, 155-163.

Mounien, L., Do Rego, J. C., Bizet, P., Boutelet, I., Gourcerol, G., Fournier, A., et al. (2009). Pituitary adenylate cyclase-activating polypeptide inhibits food intake in mice through activation of the hypothalamic melanocortin system. Neuropsychopharmacology 34, 424-435.

Murase, T., Kondo, K., Arima, H., Iwasaki, Y., Ito, M., Miura, Y., et al. (1995). The expression of pituitary adenylate cyclase-activating polypeptide (PACAP) mRNA in rat brain: possible role of endogenous PACAP in vasopressin release. $\mathrm{Neu}$ rosci. Lett. 185, 103-106.

Mustafa, T., Grimaldi, M., and Eiden, L. E. (2007). The hop cassette of the PAC1 receptor confers coupling to $\mathrm{Ca} 2+$ elevation required for pituitary adenylate cyclase-activating polypeptide-evoked neurosecretion. J. Biol. Chem. 282, 8079-8091.

Mustafa, T., Walsh, J., Grimaldi, M., and Eiden, L. E. (2010). PAClhop receptor activation facilitates catecholamine secretion selectively through 2-APB-sensitive $\mathrm{Ca}(2+)$ channels in PC12 cells. Cell. Signal. $22,1420-1426$.

Nakahara, K., Abe, Y., Murakami, T., Shiota, K., and Murakami, N. (2002). Pituitary adenylate cyclaseactivating polypeptide (PACAP) is involved in melatonin release via the specific receptor PACAP-r1, but not 
in the circadian oscillator, in chick pineal cells. Brain Res. 939, 19-25.

Nicot, A., and DiCicco-Bloom, E. (2001). Regulation of neuroblast mitosis is determined by PACAP receptor isoform expression. Proc. Natl. Acad. Sci. U.S.A. 98, 4758-4763.

Nishimoto, M., Furuta, A., Aoki, S., Kudo, Y., Miyakawa, H., and Wada, K. (2007). PACAP/PAC1 autocrine system promotes proliferation and astrogenesis in neural progenitor cells. Glia 55, 317-327.

Nomura, M., Ueta, Y., Larsen, P. J., Hannibal, J., Serino, R., Kabashima, N., et al. (1997). Water deprivation increases the expression of pituitary adenylate cyclase-activating polypeptide gene in the rat subfornical organ. Endocrinology 138, 4096-4100.

Nordstrom, K. J., Lagerstrom, M. C., Waller, L. M., Fredriksson, R., and Schioth, H. B. (2009). The Secretin GPCRs descended from the family of Adhesion GPCRs. Mol. Biol. Evol. 26, 71-84.

Norris, A. D., and Calarco, J. A. (2012). Emerging roles of alternative pre-mRNA splicing regulation in neuronal development and function. Front. Neurosci. 6:122. doi:10.3389/fnins.2012.00122

Oldham, W. M., and Hamm, H. E. (2008). Heterotrimeric G protein activation by G-protein-coupled receptors. Nat. Rev. Mol. Cell Biol. 9 , 60-71.

Onoue, S., Endo, K., Yajima, T., and Kashimoto, K. (2002). Pituitary adenylate cyclase activating polypeptide regulates the basal production of nitric oxide in PC12 cells. Life Sci. 71, 205-214.

Pantaloni, C., Brabet, P., Bilanges, B., Dumuis, A., Houssami, S., Spengler, D., et al. (1996). Alternative splicing in the N-terminal extracellular domain of the pituitary adenylate cyclase-activating polypeptide (PACAP) receptor modulates receptor selectivity and relative potencies of PACAP-27 and PACAP-38 in phospholipase C activation. J. Biol. Chem. 271, 22146-22151.

Parsons, R. L., Rossignol, T. M., Calupca, M. A., Hardwick, J. C., and Brass, K. M. (2000). PACAP peptides modulate guinea pig cardiac neuron membrane excitability and neuropeptide expression. Ann. N. Y. Acad. Sci. 921, 202-210.

Payet, M. D., Bilodeau, L., Breault, L., Fournier, A., Yon, L., Vaudry, H., et al. (2003). PAC1 receptor activation by PACAP-38 mediates $\mathrm{Ca} 2+$ release from a cAMP-dependent pool in human fetal adrenal gland chromaffin cells. J. Biol. Chem. 278, 1663-1670.

Pierce, K. L., Premont, R. T., and Lefkowitz, R. J. (2002). Seventransmembrane receptors. Nat. Rev. Mol. Cell Biol. 3, 639-650

Pilzer, I., and Gozes, I. (2006a). A splice variant to PACAP receptor that is involved in spermatogenesis is expressed in astrocytes. Ann. N. Y. Acad. Sci. 1070, 484-490.

Pilzer, I., and Gozes, I. (2006b). VIP provides cellular protection through a specific splice variant of the PACAP receptor: a new neuroprotection target. Peptides 27, 2867-2876.

Pisegna, J. R., Moody, T. W., and Wank, S. A. (1996). Differential signaling and immediate-early gene activation by four splice variants of the human pituitary adenylate cyclase-activating polypeptide receptor (hPACAP-R). Ann. N. Y. Acad. Sci. 805, 54-64; discussion 64-66.

Pisegna, J. R., and Wank, S. A. (1996). Cloning and characterization of the signal transduction of four splice variants of the human pituitary adenylate cyclase activating polypeptide receptor. Evidence for dual coupling to adenylate cyclase and phospholipase C. J. Biol. Chem. 271, 17267-17274.

Postina, R. (2012). Activation of alphasecretase cleavage. J. Neurochem. 120(Suppl. 1), 46-54.

Pugh, P. C., Jayakar, S. S., and Margiotta, J. F. (2010). PACAP/PAC(1)R signaling modulates acetylcholine release at neuronal nicotinic synapses. Mol. Cell. Neurosci. 43, 244-257.

Pugh, P. C., and Margiotta, J. F. (2006). PACAP support of neuronal survival requires MAPK- and activitygenerated signals. Mol. Cell. Neurosci. 31, 586-595.

Rat, D., Schmitt, U., Tippmann, F., Dewachter, I., Theunis, C., Wieczerzak, E., et al. (2011). Neuropeptide pituitary adenylate cyclase-activating polypeptide (PACAP) slows down Alzheimer's disease-like pathology in amyloid precursor protein-transgenic mice. FASEB J. 25, 3208-3218.

Ravni, A., Bourgault, S., Lebon, A., Chan, P., Galas, L., Fournier, A., et al. (2006). The neurotrophic effects of PACAP in PC12 cells: control by multiple transduction pathways. $J$. Neurochem. 98, 321-329.

Reglodi, D., Lubics, A., Tamas, A., Szalontay, L., and Lengvari, I. (2004). Pituitary adenylate cyclase activating polypeptide protects dopaminergic neurons and improves behavioral deficits in a rat model of Parkinson's disease. Behav. Brain Res. 151, 303-312.

Resnick, M., Segall, A., Rozic-Kotliroff, G., Lupowitz, Z., and Zisapel, N. (2008). Alternative splicing of neurexins: a role for neuronal polypyrimidine tract binding protein. Neurosci. Lett. 439, 235-240.

Ressler, K. J., Mercer, K. B., Bradley, B. Jovanovic, T., Mahan, A., Kerley, K., et al. (2011). Post-traumatic stress disorder is associated with PACAP and the PAC1 receptor. Nature 470 492-497.

Ritter, S. L., and Hall, R. A. (2009). Finetuning of GPCR activity by receptorinteracting proteins. Nat. Rev. Mol. Cell Biol. 10, 819-830.

Ronaldson, E., Robertson, D. N., Johnson, M. S., Holland, P. J., Mitchell, R., and Lutz, E. M. (2002). Specific interaction between the hop 1 intracellular loop 3 domain of the human PAC(1) receptor and ARF. Regul. Pept. 109, 193-198.

Ryu, S., Mahler, J., Acampora, D. Holzschuh, J., Erhardt, S., Omodei, D., et al. (2007). Orthopedia homeodomain protein is essential for diencephalic dopaminergic neuron development. Curr. Biol. 17, 873-880.

Sah, V. P., Seasholtz, T. M., Sagi, S. A., and Brown, J. H. (2000). The role of Rho in $\mathrm{G}$ protein-coupled receptor signal transduction. Annu. Rev. Pharmacol. Toxicol. 40, 459-489.

Schnorr, S. J., Steenbergen, P. J., Richardson, M. K., and Champagne, D. L (2012). Measuring thigmotaxis in larval zebrafish. Behav. Brain Res. 228, 367-374

Shi, G. X., Jin, L., and Andres, D. A (2010). Src-dependent TrkA transactivation is required for pituitary adenylate cyclase-activating polypeptide 38-mediated Rit activation and neuronal differentiation. Mol. Biol. Cell 21, 1597-1608.

Shi, G. X., Rehmann, H., and Andres, D. A. (2006). A novel cyclic AMP-dependent Epac-Rit signaling pathway contributes to PACAP38mediated neuronal differentiation. Mol. Cell. Biol. 26, 9136-9147.

Shioda, S., Yada, T., and Nakajo, S. (1998). PACAP increases cytosolic calcium in vasopressin neurons: synergism with noradrenaline. Ann. N. Y. Acad. Sci. 865, 427-430.

Shioda, S., Yada, T., Nakajo, S., Nakaya, K., Nakai, Y., and Arimura, A. (1997). Pituitary adenylate cyclaseactivating polypeptide (PACAP) a novel regulator of vasopressincontaining neurons. Brain Res. 765, 81-90.
Shneider, Y., Shtrauss, Y., Yadid, G., and Pinhasov, A. (2010). Differential expression of PACAP receptors in postnatal rat brain. Neuropeptides 44, 509-514.

Shyu, J. F., Inoue, D., Baron, R., and Horne, W. C. (1996). The deletion of 14 amino acids in the seventh transmembrane domain of a naturally occurring calcitonin receptor isoform alters ligand binding and selectively abolishes coupling to phospholipase C. J. Biol. Chem. 271, 31127-31134.

Simon, M. I., Strathmann, M. P., and Gautam, N. (1991). Diversity of G proteins in signal transduction. Science $252,802-808$.

Smith, C. B., and Eiden, L. E. (2012). Is PACAP the major neurotransmitter for stress transduction at the adrenomedullary synapse? J. Mol. Neurosci. 48, 403-412.

Spengler, D., Waeber, C., Pantaloni, C. Holsboer, F., Bockaert, J., Seeburg, P. H., et al. (1993). Differential signal transduction by five splice variants of the PACAP receptor. Nature 365, 170-175.

Steenbergen, P. J., Richardson, M. K., and Champagne, D. L. (2011). Patterns of avoidance behaviours in the light/dark preference test in young juvenile zebrafish: a pharmacological study. Behav. Brain Res. 222, $15-25$.

Ster, J., De Bock, F., Guerineau, N. C., Janossy, A., Barrere-Lemaire, S., Bos, J. L., et al. (2007). Exchange protein activated by cAMP (Epac) mediates cAMP activation of p38 MAPK and modulation of $\mathrm{Ca} 2+-$ dependent $\mathrm{K}+$ channels in cerebellar neurons. Proc. Natl. Acad. Sci. U.S.A. 104, 2519-2524.

Stroth, N., and Eiden, L. E. (2010). Stress hormone synthesis in mouse hypothalamus and adrenal gland triggered by restraint is dependent on pituitary adenylate cyclaseactivating polypeptide signaling. Neuroscience 165, 1025-1030.

Stumm, R., Kolodziej, A., Prinz, V., Endres, M., Wu, D. F., and Hollt, V. (2007). Pituitary adenylate cyclase-activating polypeptide is up-regulated in cortical pyramidal cells after focal ischemia and protects neurons from mild hypoxic/ischemic damage. J. Neurochem. 103, 1666-1681.

Sun, S., Zhang, Z., Fregoso, O., and Krainer, A. R. (2012). Mechanisms of activation and repression by the alternative splicing factors RBFOX1/2. RNA 18, 274-283. 
Tanaka, K., Shibuya, I., Harayama, N., Nomura, M., Kabashima, N., Ueta, Y., et al. (1997). Pituitary adenylate cyclase-activating polypeptide potentiation of $\mathrm{Ca} 2+$ entry via protein kinase $\mathrm{C}$ and A pathways in melanotrophs of the pituitary pars intermedia of rats. Endocrinology 138, 4086-4095.

Tanaka, K., Shibuya, I., Uezono, Y., Ueta, Y., Toyohira, Y., Yanagihara, N., et al. (1998). Pituitary adenylate cyclase-activating polypeptide causes $\mathrm{Ca} 2+$ release from ryanodine/caffeine stores through a novel pathway independent of both inositol trisphosphates and cyclic AMP in bovine adrenal medullary cells. J. Neurochem. 70, 1652-1661.

Taupenot, L., Mahata, M., Mahata, S. K., and O'Connor, D. T. (1999). Time-dependent effects of the neuropeptide PACAP on catecholamine secretion: stimulation and desensitization. Hypertension 34, 1152-1162.

Tsukiyama, N., Saida, Y., Kakuda, M., Shintani, N., Hayata, A., Morita, Y., et al. (2011). PACAP centrally mediates emotional stress-induced corticosterone responses in mice. Stress $14,368-375$.

Ule, J., Ule, A., Spencer, J., Williams, A., Hu, J. S., Cline, M., et al. (2005). Nova regulates brain-specific splicing to shape the synapse. Nat. Genet. $37,844-852$.

Ushiyama, M., Ikeda, R., Sugawara, H., Yoshida, M., Mori, K., Kangawa, K., et al. (2007). Differential intracellular signaling through $\mathrm{PACl}$ isoforms as a result of alternative splicing in the first extracellular domain and the third intracellular loop. Mol. Pharmacol. 72, 103-111.

Ushiyama, M., Ikeda, R., Yoshida, M., Mori, K., Kangawa, K., Sugawara, H., et al. (2010). Alternative splicing of the pituitary adenylate cyclase-activating polypetide (PACAP) receptor contributes to function of PACAP-27. J. Mol. Neurosci. 42, 341-348.

Vallejo, M. (2009). PACAP signaling to DREAM: a cAMP-dependent pathway that regulates cortical astrogliogenesis. Mol. Neurobiol. 39, 90-100.

Vaudry, D., Basille, M., Morel, A. F., Aubert, N., Botia, B., Allais, A., et al. (2007). Neurotrophic effects of PACAP in the cerebellar cortex. $J$. Mol. Neurosci. 33, 312-312.

Vaudry, D., Falluel-Morel, A., Bourgault, S., Basille, M., Burel, D., Wurtz, O., et al. (2009). Pituitary adenylate cyclase-activating polypeptide and its receptors: 20 years after the discovery. Pharmacol. Rev. 61, 283-357.

Vaudry, D., Falluel-Morel, A., Leuillet, S., Vaudry, H., and Gonzalez, B. J. (2003). Regulators of cerebellar granule cell development act through specific signaling pathways. Science 300, 1532-1534.

Vaudry, D., Gonzalez, B. J., Basille, M., Pamantung, T. F., Fournier, A., and Vaudry, H. (2000). PACAP acts as a neurotrophic factor during histogenesis of the rat cerebellar cortex. Ann. N. Y. Acad. Sci. 921, 293-299.

Villalba, M., Bockaert, J., and Journot, L. (1997). Pituitary adenylate cyclaseactivating polypeptide (PACAP-38) protects cerebellar granule neurons from apoptosis by activating the mitogen-activated protein kinase (MAP kinase) pathway. J. Neurosci. 17, 83-90.

Wang, W., and Lufkin, T. (2000). The murine Otp homeobox gene plays an essential role in the specification of neuronal cell lineages in the developing hypothalamus. Dev. Biol. 227, 432-449.

Waschek, J. A. (2003). Multiple actions of pituitary adenylyl cyclase activating peptide in nervous system development and regeneration (vol 24, pg 14, 2002). Dev. Neurosci. 25, 393-393.

Waschek, J. A., DiCicco-Bloom, E. M., Lelievre, V., Zhou, X., and Hu, Z.
(2000). PACAP action in nervous system development, regeneration, and neuroblastoma cell proliferation. Ann. N. Y. Acad. Sci. 921, 129-136.

Watkins, H. A., Au, M., and Hay, D. L. (2012). The structure of secretin family GPCR peptide ligands: implications for receptor pharmacology and drug development. Drug Discov. Today 17, 1006-1014.

Wei, Y., Martin, S. C., Heinrich, G., and Mojsov, S. (1998). Cloning and functional characterization of PACAPspecific receptors in zebrafish. Ann. N. Y. Acad. Sci. 865, 45-48.

West, A. E., Chen, W. G., Dalva, M. B., Dolmetsch, R. E., Kornhauser, J. M., Shaywitz, A. J., et al. (2001). Calcium regulation of neuronal gene expression. Proc. Natl. Acad. Sci. U.S.A. 98, 11024-11031.

Winters, S. J., and Moore, J. P. (2011). PACAP, an autocrine/paracrine regulator of gonadotrophs. Biol. Reprod. 84, 844-850.

Xue, C., Hsueh, Y. P., and Heitman, J. (2008). Magnificent seven: roles of $G$ protein-coupled receptors in extracellular sensing in fungi. FEMS Microbiol. Rev. 32, 1010-1032.

Yano, M., Hayakawa-Yano, Y., Mele, A., and Darnell, R. B. (2010). Nova2 regulates neuronal migration through an RNA switch in disabled-1 signaling. Neuron 66, 848-858.

Yeo, G. W., Xu, X., Liang, T. Y., Muotri, A. R., Carson, C. T., Coufal, N. G., et al. (2007). Alternative splicing events identified in human embryonic stem cells and neural progenitors. PLoS Comput. Biol. 3:e196. doi:10.1371/journal.pcbi.0030196

Zhang, C., Zhang, Z., Castle, J., Sun, S., Johnson, J., Krainer, A. R., et al. (2008). Defining the regulatory network of the tissue-specific splicing factors Fox-1 and Fox-2. Genes Dev. 22, 2550-2563.

Zhang, X., and Eggert, U. S. (2013). Non-traditional roles of $G$ protein-coupled receptors in basic cell biology. Mol. Biosyst. 9, 586-595.

Zheng, S., Gray, E. E., Chawla, G. Porse, B. T., O'Dell, T. J., and Black, D. L. (2012). PSD-95 is posttranscriptionally repressed during early neural development by PTBP1 and PTBP2. Nat. Neurosci. 15, 381-388.

Zmijewski, M. A., and Slominski, A. T. (2009). CRF1 receptor splicing in epidermal keratinocytes: potential biological role and environmental regulations. J. Cell. Physiol. 218, 593-602.

Zmijewski, M. A., and Slominski, A. T. (2010). Emerging role of alternative splicing of CRF1 receptor in CRF signaling. Acta Biochim. Pol. 57, 1-13.

Conflict of Interest Statement: The authors declare that the research was conducted in the absence of any commercial or financial relationships that could be construed as a potential conflict of interest.

Received: 25 November 2012; accepted: 24 April 2013; published online: 21 May 2013.

Citation: Blechman $J$ and Levkowitz $G$ (2013) Alternative splicing of the pituitary adenylate cyclase-activating polypeptide receptor PACl: mechanisms of fine tuning of brain activity. Front. Endocrinol. 4:55. doi: 10.3389/fendo.2013.00055

This article was submitted to Frontiers in Neuroendocrine Science, a specialty of Frontiers in Endocrinology.

Copyright () 2013 Blechman and Levkowitz. This is an open-access article distributed under the terms of the Creative Commons Attribution License, which permits use, distribution and reproduction in other forums, provided the original authors and source are credited and subject to any copyright notices concerning any third-party graphics etc. 